Poverties. Brazil4.doc $\quad 10,100$ including references 22 pages 6 August 05

Paper for the International Conference on Multidimensional Poverty:

Brasilia August 29-31 2005

\title{
Participation, Pluralism and Perceptions of Poverty
}

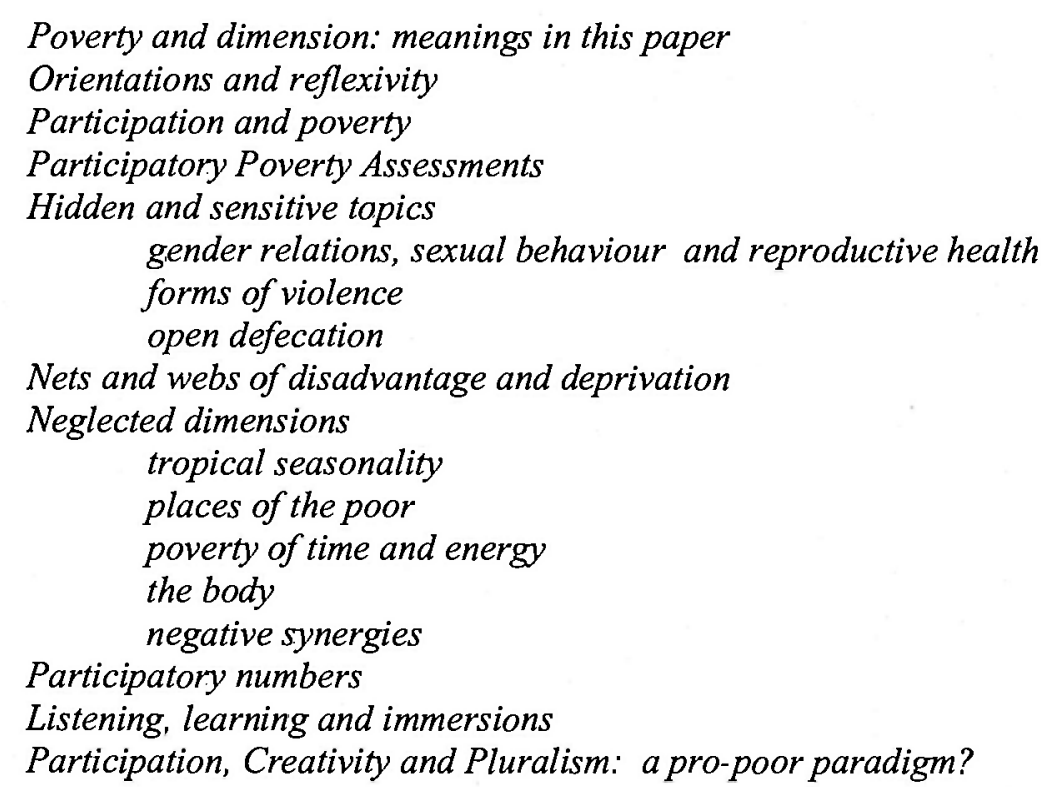

Since I may be the only person presenting in this conference on participatory approaches and methods, I have attempted an overview of participatory practices, evidence and associated ideas and insights about poverty. I recognise that the paper is both too long and the coverage woefully inadequate. But I hope the sources cited will encourage readers and make it easier for them to check what I am saying and to follow up if they wish and as I hope they will.

Poverty and dimension: meanings in this paper

In any paper, meanings of words are both problems and opportunities. One common problem is when an author uses the same word in more than one sense. Another, perhaps even more common, is when readers attribute meanings to words which are different from those intended by the author. On the flip side, there is the opportunity for an author to be consistent in usage and meanings: this I shall attempt but surely fail to do. Another opportunity is to say at the outset what words are going to be used to mean. This I shall now try to do with the two words which are central in this conference: poverty, and dimension. I am not in the least saying that this is what they ought to mean, or what others should mean by them, only that these are the meanings intended here.

Poverty. In this paper, I take poverty to mean bad condition or experience of life. This is more than material poverty or lack. It is the meaning implied by the statement with which the World Development Report (WDR) 2000/01 Attacking Poverty opens "Poverty is pronounced deprivation in wellbeing" (World Bank 2000: 15). "Multidimensional poverty" is then the same as "multidimensional deprivation".' Well-being I take to be the experience of good quality of life, and ill-being, its opposite, the experience of bad quality of life. 
It can be objected that with this definition, a fat cat with money pouring out of his (most are men) ears but whose mind is a waking nightmare and whose relations with his wife are horrible could be said to be poor or suffering from poverty. Yet in commonsense terms we would never

describe him as poor. This is, however, not a serious problem when we take account of the nets or webs of deprivation, powerlessness and disadvantage (see Nets and Webs of Deprivation and Disadvantage below). The fat cat does not suffer significantly from the interactions of these. So the definition of poverty can be qualified so that it applies to bad conditions and experiences of life in which material and other deprivations and disadvantages interact and reinforce each other as they do in the nets and webs.

Dimension. In the literature this is used in at least three senses.

First, the Research Group on Wellbeing in Developing Countries at the University of Bath (White and Pettit in press) describes three dimensions of wellbeing, and by implication of its opposites, illbeing, poverty or deprivation. These are subjective, objective, and interactive or process. Subjective can be taken to mean what is experienced, objective to refer to conditions or cause outside a person, and interactive or process to encompass how subjective (internal and experiential) and objective (external) affect each other.

A second sense of dimension is that in the WDR 2000/2001 (see e.g. v, 1, 15 and passim) which "sets out actions to create a world free of poverty in all its dimensions". The multiple deprivations listed in the Report, besides low income or consumption, include lack of education, health, food and shelter, fear, powerlessness and voicelessness. And the WDR says that there is "a powerful case for bringing vulnerability and its management to center stage" (ibid 32). The WDR implicitly separates some of the more experiential dimensions of poverty from their determinants (e.g. ibid:34).

A third and broader usage includes the first two and extends dimension to include causes to a greater extent. Thus, for example, "Corrupt and arbitrary governance constitutes a significant factor that defines and contributes to the various other dimensions of poverty" (Parasuraman et al 2003: 33). This was also the sense which evolved out of the Voices of the Poor process, in which participatory approaches and methods were used to enable poor people in close to 300 communities in 23 countries to express and analyse their realities (Narayan et al 2000). After stating that "The dimensions of deprivation are multiple", ten "Dimensions of Powerlessness and Illbeing" were elicited and described:

Capabilities:

lack of information, education, skills, confidence

Livelihoods and assets:

Places:

precarious, seasonal, inadequate

The body:

isolated, risky, unserviced, stigmatised

Gender relations:

hungry, exhausted, sick, poor appearance

Social relations:

troubled and unequal

Security:

discriminating and isolating

lack of protection and peace of mind

Behaviours:

disregard and abuse by the more powerful

Institutions:

disempowering and excluding

Organizations of the poor: weak and disconnected

(Narayan et al 2000: 248-9 and figure 2 below)

Many dimensions can be identified, as above. They may be physical, material, social and/or psychological, and can be experiential (subjective?), external to a person (objective?), related to 
interaction or process, or a cause, or often some combination of these. There seems no gain from restricting the meaning of dimension. In this paper I shall use it in these various and several senses, relying on other words and the context to indicate particular meaning.

In a spirit of pluralism I recognise and celebrate the fact that there will be other meanings and other categories, not least those of Sen (e.g.1999), represented, expressed and used, in this conference. I am not asserting any sort of primacy to those I struggle with in this paper, only trying to be consistent in their use.

\section{Orientations and Reflexivity}

It gives a useful perspective to recognise how far we have come. A well-balanced view of professional views of poverty is beyond my competence. What stands out, though, is how the reductionist money-metric view of poverty has been, and to some extent remains, disproportionately dominant is much development discourse. For some economists and others it is sort of a bedrock; for others, a sort of default mode. Reviewing the important debates on poverty and the poverty line in India Tony Beck observed (1993: 16) that "..the central preoccupation of the majority of authors on poverty has been the accuracy of the statistics and the statistical techniques used". A tempting caricature of the concept of poverty implied by such debates could be of a top-down, centre-outwards, ivory tower, mathematical construct, overfed and driven by questionnaires, statistics, computers, regressions, equations, graphs and tables. In this view, it could be seen as sustained by erudite, incestuous and self-reproducing systems of high status organisations and departments, and by teaching, textbooks, international conferences, prestigious journals and rigorous professional peer review. Economists, it might be suggested, construct their own reality of poverty based on reported income or consumption, provoking the verse:

Economists have come to feel

What can't be measured isn't real

The truth is always an amount

Count numbers, only numbers count

But those, like myself, who enjoy writing this sort of stuff about economists, have to look at ourselves. We too find it useful and indeed necessary to refer to poverty lines; and their accuracy and what they represent do matter. We too have our biases and predispositions. Arguably, any writing on development should be preceded by a reflexive paragraph outlining those of which the author is aware. Let me list some of mine. As a lapsed biologist and historian, and now undisciplined social scientist, I take pleasure, and have sustained a livelihood, by looking for gaps between professions and aspects of realities that seem to have been overlooked or understudied. I recognise that I am liable to exaggerate the importance of such gaps, and am vulnerable to glee when I believe I have discovered a misperception of "normal" professionalism and professionals. In my view, numbers and statistics are important, but often more flawed than their users recognise. I tend to privilege the knowledge, values and abilities of poor and excluded people over those of established groups, especially academics and powerful old men. I have been repeatedly astonished at the insights and capabilities that have been revealed by participatory behaviours, attitudes, approaches and methods. So about these predispositions and biases at least (and there are surely others) readers have now been alerted and warned. 


\section{Participation and Poverty}

In the past decade and a half we have come a long way in the invention, evolution and spread of participatory approaches and methods and their contributions to understanding poverty. A new pluralism of methodology and perception has opened up. A thousand flowers have bloomed. At the same time, especially when spread by big bureaucracies, many have turned into weeds. In parallel, though, there have been innumerable examples of good practice. Sourcebooks, guides and manuals have proliferated, and have then increasingly been superseded by eclectic creativity. Those participatory methodologies which have become best known and most widespread include: Participatory Action Research, PRA (originally participatory rural appraisal, now often participatory reflection and action) and PLA (participatory learning and action), Participatory Technology Development, Appreciative Inquiry, Planning for Real, Popular Education, Popular Theatre, Reflect and various forms of Participatory Monitoring and Evaluation (PM and E)". Well facilitated, in various forms and combinations, these to varying degrees can enable and empower poor and marginalised people to conduct and learn from their own analyses, express their values and priorities, and plan, act, monitor and evaluate for themselves. They have also provided many insights into dimensions of poverty.

Five clusters of related innovation and insight stand out:

Participatory Poverty Assessments

Hidden and sensitive topics

Nets and webs of disadvantage and deprivation

Participatory numbers

Listening, learning and immersions

There is no way these can be adequately covered in a paper of this length. Instead, I shall attempt to summarise them and give references to what seem to me to some key sources.

\section{Participatory Poverty Assessments}

Participatory Poverty Assessments (PPAs) evolved in the early 1990s, notably in Ghana (1993-4), Zambia (1993-) and South Africa (1995-) and have since become widespread, with probably hundreds now complete counting those at subnational as well as national levels. By 2002 more than 60 countries had undertaken PPAs with assistance from the World Bank, with a similar number supported by other agencies (Robb 2002: 3). Increasingly PPA-type studies have been carried out at subnational levels, for example in Bolangir District in Orissa,India (PRAXIS 2001).

$A$ PPA was described in The Rough Guide to PPAs (Norton et al 2001: 6) as "an instrument for including poor people's views in the analysis of poverty and the formulation of strategies to reduce it through public policy". In many of these, focus groups were combined with PRA methods of analysis. Groups have been facilitated to create and analyse their realities often using visuals and tangibles for methods such as participatory mapping, preference ranking, matrix scoring, Venn diagramming, wealth or wellbeing ranking, and many others. They have covered many aspects of life and experience such as poor people's priorities, access and institutions, gender relations, causal linkages, seasonal variations, and trends and changes.

Repeatedly, PPAs have opened up aspects of poverty which had been relatively overlooked or given inadequate priority. Reviews of PPAs (Booth et al 1998: 5-7) found that they highlighted: 
- A sense of isolation, from services, markets, government institutions and information, with physical isolation a key factor

- The key importance of water supplies

- Security of life and livelihood as a primary concern

- Access to curative health as a consistently high priority

- Local visions of poverty relating to prevailing community norms

- Differential vulnerability according to inherent or socially constructed characteristics of individuals (gender, age, childlessness, health status, disability and individual pathologies such as drunkenness)

- Hunger and dietary inadequacy as a distinct dimension of deprivation

- The seasonality of access and vulnerability

- Intra-household poverty dynamics

- The decline of traditional, and insufficiency of alternative, safety nets

- Community-level poverty versus household or individual poverty

Caroline Robb concluded her review of PPAs (second edition, 2002: 104-5)

"The moral imperative for giving the poor a voice in the poverty debate is self-evident. The bonus is that engaging with the poor also leads to better technical diagnosis of problems and implementation of solutions. Through PPAs, the poor deepen our understanding of poverty and can influence policymaking. This new approach challenges traditional power relations... when undertaken in an environment of increased trust, PPAs can present opportunities for a more open dialogue and greater understanding between the powerless and those in power."

The processes for Poverty Reduction Strategy Papers (PRSPs) which have superseded PPAs in prominence have been criticised for inadequate consultation. Some, however, have drawn on PPAs, a clear example being Uganda where "the PPA predated the PRSP concept, but was used extensively in revising the national strategy, which became the PRSP" (McGee et al 2002: 8). In a remarkable evolution in Rwanda, a PPA process, ubudehe, has been developed and spread in which each commune conducts its own PPA leading to direct local learning and collective action. This process, with trained facilitators, is anticipated to have covered the whole country by the end of 2005 (Joseph 2005). This is but one example of the many forms and potentials of PPAs.

\section{Hidden and Sensitive Dimensions}

Participatory methods, creatively evolved and carefully facilitated, have opened up aspects of life which have usually been thought too private, sensitive or dangerous to make public or to analyse. An early example (see also below) was wealth or wellbeing ranking, in which members of a community typically first draw a social map showing all households, then list these on cards, and then sort them into piles according to degrees of wealth or more usually some concept of wellbeing. Middle class urban professionals often regard this as either impossible, or unethical, supposing it will be demeaning and humiliating for those who are worse off. To an extraordinary degree these fears have repeatedly proved unfounded. Three other areas are gender relations and sexual and reproductive wellbeing, violence, insecurity and social abuses, and open defecation.

The first example is the related areas of gender relations, sexual behaviour and sexual and reproductive well-being. Participatory approaches and methods have proved potent in bringing these into the open, and empowering women to take action. Gender relations, and how they have been changing, were a major theme in the Voices of the Poor study (Narayan et al 2001 chapter 6 
pp 109-132). Much has been explored and documented as never before in Realizing Rights: transforming approaches to sexual and reproductive well-being (Cornwall and Welbourn 2002). The lives and realities of those who are marginalised, despised, excluded and ignored have been brought out into the light. Sex workers, for example, come to life as people like other people, for whom respect, security and good relations matter as much, if not more, than they do for others. Participatory approaches to HIV/AIDS, especially through the group processes known as Stepping Stones (Welbourne 1995, 2002) have brought what was hidden or unspoken into the open, with frank talk about sex and death, concern for sensitive behaviour and relationships, acceptance of HIV-positive women and men, and counselling and care for the sick and dying. Participatory approaches and methods have also been developed for HIV/AIDS work with drug users (International HIV/AIDS Alliance 2003). Other areas are the sexual behaviours and preferences of adolescents ${ }^{\mathrm{iv}}$ and of prepubescent children (unknown to their parents).

The second area is violence, physical insecurity and social abuses. Participatory studies of violence in Jamaica, Guatemala and Colombia have broken new ground, revealing wide differences between beliefs of policy-makers about forms of violence and the realities experienced by ordinary people. In Peru, participatory time lines, matrices and maps were used in Ayacucho as part of the Colectivo Yuyarisu ('We remember') process of the Truth Commission (Comision de la Verdad y Justicia): using these methods, over 100 groups recollected and reconstructed human rights violations which had taken place in the era of political violence 1980 94 (Francke 2003 and pers comm). In many contexts, domestic abuse and violence against women has been brought out into the open. An early example was an all-women's PRA activity in Tamil Nadu in 1990 (pers. comms. Sheelu Francis and John Devavaram) in which women mapped households and marked with a yellow circle those where the husband was a drunkard. The Voices of the Poor study included perceived prevalence and trends of domestic violence against women. Another illustration is the Internal Learning System introduced into parts of Indiav. Women individually and in groups keep visual diaries which they update every six months. In these they score from 1 to 5 for aspects of quality of life such husbands drinking, domestic violence, Dalits having to drink out of separate glasses, Dalits being made to carry dead bodies or dead animals, and whether a girl can select her life partner (pers. comms. Vimalanathan, S. Nagasundari and H. Noponen).

A third example is open defecation, widespread in South and Southeast Asia and a major source of sickness and mortality, and illbeing for women who lack access to the privacy of a latrine. They are subject to gross gender discrimination being compelled by custom, unlike men, to go unseen which without latrines means only before dawn or after nightfall. New participatory approaches are now enabling communities to confront and face the realities, often spurring them into action (Kar 2003). Community members are facilitated to make defecation maps, walk transects, inspect the defecation areas, confront the reality, draw flow diagrams, calculate the cartloads of shit produced and the amounts ingested, and are encouraged to take action on their own. The number of communities in South Asia that have now proudly declared themselves open defecation free now numbers thousands. The gains for the well-being of women is suggested by an inscription on a wall in a totally sanitised village in Maharashtra: 'Daughters from our village are not married to villages where open defecation is practised'. In rural South Asia, where open defecation is widespread, the sheer scale of the potential gains in health, reduced mortality, and wellbeing for millions of women, children and men is so vast that it is difficult fully to appreciate.

The importance of opening up these subjects can scarcely be exaggerated. When they are not surfaced, analysed and confronted, much avoidable illbeing persists. Conversely, the potential for enhanced well-being from improving sexual and gender relations, from tackling and reducing or eliminating violence in its many forms, and from ending open defecation with gains in health and 
especially for the well-being especially for women and children but also for men - each of these can only be described as phenomenal. Participatory approaches and methods, well facilitated, cannot solve these alone; but there is enough evidence now to realise that they can establish bridgeheads with the possibility of becoming transformative movements which spread on their own.

\section{Nets and webs of disadvantage and deprivation}

We now come to the issue of the multiplicity of dimensions of poverty. When dimension is used in the inclusive sense of this paper, it includes many aspects of disadvantage. In the analysis of the Voices of the Poor study we faced difficult practical issues of how to analyse a large amount of data, most of it qualitative, but some also (see below, next section) amenable to aggregation and quantification ${ }^{\mathrm{vi}}$. We were continually impressed by how the dimensions of deprivation which emerged from the participatory data were interlinked, and we increasingly saw these links as a net or web in which poor people were trapped. Two diagrams were published (figures 1 and 2). ${ }^{\mathrm{vu}}$ And two others were not (figures 3 and 4).

Figure 1. Development as good change: From illbeing to wellbeing, was a manifestation of pentaphilia (the love of $5 \mathrm{~s}$ of a thing) a condition from which I have been unable to rid myself. Using it, we sought to express five composite dimensions of illbeing and wellbeing, and their interlinkages. Development could be seen as shifting from illbeing to wellbeing with equity, with interventions to enhance wellbeing possible at any of the five points.

[figure 1 about here]

Figure 2, Dimensions of powerlessness and illbeing, expanded the circles to ten

As the diagram indicates, each of these in turn can take various forms. And combining in powerlessness symbolised by the net

[figure 2 about here]

By specifying these characteristics of disadvantage, figure 2 again raises a potential agenda for intervention with any one of them, and questions of how they interlink and reinforce each other In any story of the life of a poor person, linkages can be traced.

The versatility and power of these ways of presenting multiple dimensions and causal links can also be illustrated with two further diagrams.

Figure 3, also inspired by the Voices experience (and in part shown in Narayan et al 2000: 97) shows two body syndromes. These express several ways in which a weak or hungry body can be part of self-reinforcing syndrome, including reducing the power to bargain, and how less money can mean delayed and lower quality medical treatment. These were both aspects of disadvantage which the Voices evidence presented.

[figure 3 about here]

Figure 4 may be regarded by some as over the top in terms of complexity. However, all 13 of these dimensions

- material lack

- vulnerability and insecurities

- bad social relations

- physical weakness - the body, exhaustion

- location - places of the poor

- poverty of time 
- seasonal dimensions

- capabilities

- disregard and abuse by the more powerful

- ascribed and legal inferiority

- lack of information

- lack of access to services

- lack of political clout

have been articulated and diagrammed by poor people, using variations and combinations of mapping, listing, Venn diagrams, pie diagrams, pile sorting, matrix scoring, pairwise ranking, time lines and seasonal diagrams, wealth and wellbeing ranking and sorting.

They do, though, raise analytical and practical questions. We can ask whether the many aspects and linkages presented are credible, and how many of them are found and function for any person, group or set of conditions. If we conflate or eliminate dimensions, are we then in danger of failing to identify crucial disadvantages? As the diagram indicates, each of these in turn can take various forms. Another question is whether figures 2 and 4 overstress the negative, in ways in which figures 1 and 3 do not because they indicate the potential for transitions (though, of course, these can go either way).

A question remains: whose analysis and categories are to be privileged? These are "ours", those of professionals who are not themselves poor. The words, concepts, categories and priorities of poor people, especially illustrated by the way they were elicited and expressed in the Voices of the Poor, were rich and varied, but with commonalities. There are trade-offs to be puzzled over, between "their" realities and ours, between local participatory diversity and commensurability for aggregation, and between many categories representing poor people's realities, and fewer categories more manageable for outsider professionals.

\section{Four neglected dimensions}

Four dimensions have been so relatively neglected in the professional literature of which I am aware, that I will touch on them here.

\section{Tropical seasonality.}

The interacting seasonal disadvantages include: ${ }^{\text {vii }}$

- hard work in cultivation

- sickness (malaria, Dengue fever, diarrhoeas, skin sores and diseases, snake bite, Guinea worm disease...

- lack of food. The hungry season

- poor quality and rapidly contaminated food

- physical weakness and exhaustion from combinations of the above

- shortage of money, loans in kind with very high implicit interest rates

- isolation with difficult or no access to markets and medical treatment

- late pregnancy and childbirth

- shelter and housing collapsing, leaking, flooded

- wet and cold

- the high opportunity cost of not being able to work

- neglect and exposure of children 
Season-proofed as they are against all of these, professionals living in urban centres underperceive the multiple interactions of disadvantage for poor people living in rural areas during tropical rains, especially those areas which are "remote". During the rains, travel is often restricted to tarmac roads. Those off the tarmac and especially those "cut off" during the rains, are not visited, met or heard.

\section{Places of the poor.}

A whole chapter in Voices of the Poor (Narayan et al 2000: 71-88) came to be concerned with the places where poor people live and work. This was not foreseen in the planning of the study, but emerged as the findings were collected and sorted. The places where poor people live suffer combinations of isolation, lack of infrastructure, lack of services, crime, pollution, and vulnerability to disasters like drought, floods and landslips. Stigma of urban place can mean that place of residence must be concealed or dissembled when applying for a job. Inordinate amounts of time may be required for obtaining basics like water. The Chronic Poverty Report 2004-05 devotes a whole chapter (CPRC 2005: 26-35) to "Where do chronically poor people live?" and does a service by describing and analysing spatial poverty traps, their ecological characteristics, poor infrastructure, weak institutions and political isolation. Place, whether rural or urban, as an interlocking dimension of deprivation is so obvious that it is strange that it has not received more prominence. It should be harder to overlook now that it has been named. ${ }^{1 x}$

\section{Poverty of time and energy}

Some of the poorest wish they had work. A very poor woman in a Bangladesh village said:

"These days I have no work," she complains. "If we had land, I would always be busy husking rice, grinding lentils, cooking three times a day. You've seen how hard Jolil's wife works, haven't you? I have nothing to do, so I watch the children and worry. What kind of life is that?"

$$
\text { Hartmann and Boyce 1983: 166-7) }
$$

There can be poverty of too much time, and poverty of too little. The evidence from the Voices of the Poor study suggested that unwelcome surplus time was becoming more common for men, with unemployment, and poverty of both time and energy becoming more common for women. This latter poverty of time and energy was recognised in the South African PPA (May with others 1998: 108-109). It has become more acute for many women as they have become breadwinners in addition to their domestic and reproductive roles (Narayan et al 2000: 111-4). When asked what her dream was, a poor rural woman in Zambia said that it was to be able to go to town, spend time with her friends, and come back again (PRA Report video).

\section{The body}

Deriving from their review of over 250 life-stories of poor people, Parasuraman and his coauthors devote a chapter of Listening to People Living in Poverty to "The Labouring Body" (274297), which they point out is often the only resource a person living in poverty is able to use.

"The continuous exertion of their bodies in labour that is underpaid and undervalued leaves them exhausted. Their work is hazardous, seasonal and leaves them vulnerable to outside harm. They are forced to use and sell their bodies as an instrument. They rarely have time to recuperate or rest, and are reduced to what their bodies can do. These processes inscribe on their bodies and leave them to diseases, degenerating illnesses and death" (ibid:293) 
The central importance of the body to most poor people has tended to be under recognised. The slogan at the head of a poster of the trade union SEWA (the Self-Employed Women's Association) in India reads: OUR BODIES ARE OUR CAPITAL. The body is more important to people living in poverty than it is to professionals. For many, it is their most important asset. But it is at the same time vulnerable, uninsured and indivisible. It has often been weakened by life experiences. It is exceptionally exposed and vulnerable - to hard and dangerous work and accidents, to violence, to sickness, to lack of nutrition, overwork and exhaustion. With an accident or illness it can flip suddenly from being main asset to liability, needing payment for treatment and having to be fed and cared for. It is a recurrent finding that many fall into bad conditions of deep poverty because of what has happened to their bodies. Yet in general, the priority to poor people of quick, effective and affordable treatment has been under-recognised by professionals. In addition to human and ethical aspects, it may cost much less, and be more feasible, to provide good curative services to enable poor people to avoid becoming poorer than it is, once they are poorer, to enable them to claw their way back up again.

\section{Negative synergies}

These four neglected dimensions, like others, interact with negative synergies.. A poor woman in the Gambia, referring to what could happen during the agricultural season of the rains, said: "Sometimes we are overcome by weeds through sickness or accidents". With seasonal vulnerability of the body, in places which are isolated or cut off, and with seasonal poverty of time and energy when time and energy have high opportunity costs, the disadvantages are compounded, but in ways which are not readily visible to professionals. It is a cruel twist that poor people are kept waiting in clinics while better dressed middle class people see health staff straight away ${ }^{x_{1}}$. In terms of human wellbeing foregone by waiting, the time of the poor people can be far, far more valuable. But this is neither recognised nor acted on. Following any logic of optimising wellbeing, it is the middle classes who should have to wait.

\section{Participation and numbers}

In recent years increasing attention has been paid to combining qualitative and quantitative methods in research (e.g. Booth et al 1998; Marsland et al 2000; Kanbur 2003).

Complementarities have been recognised between the depth and detail contributed by qualitative research and the representativeness and statistical robustness contributed by quantitative research $^{\mathrm{xi1}}$. The benefits of such combinations are not now seriously in dispute. They do, though, tend to overlook the power and potential of participatory approaches and methods. In this connection, two assumptions are still quite common: first, that participatory approaches only generate qualitative insights; and second, that quantitative data can only be produced by questionnaire surveys or scientific measurement.

To the contrary, numerous experiences have shown both these assumptions to be false. Since the early 1990s, a quiet tide of innovation has developed a rich range of participatory ways by which local people can themselves produce numbers ${ }^{\mathrm{xii}}$. The methodological pioneers have rarely recognised the full significance of what they have been doing and have often not written up what they have done, or made it easy for others to learn from them. They have worked in the NE quadrant of figure 5 that has been largely overlooked by mainstream professions and professionals. The results have been as striking and exciting as they have been unrecognised in professional mainstreams.

[figure 5 about here] 
There are now many examples of numbers being generated by participatory processes and of statistical analysis of these ${ }^{\mathrm{x} 1 \mathrm{v}}$. The evidence to date indicates that numbers generated by participatory processes are usually more accurate and more useful than those from questionnaires. Some questionnaires will always be needed, and some, especially time series like the National Sample Survey in India, should surely continue. But for most investigations needing numbers questionnaires may now best be only a last resort. Since this statement may be greeted with scepticism, let me lay out some of the experience and evidence.

Participatory analytical activities and applications can generate numbers through counting, measuring, estimating, valuing, ranking, and scoring. Making comparisons is often involved, giving numbers or scores to indicate relative values. Analytical activities are many, for example:

\author{
- Mapping \\ - Modelling \\ - Pile sorting \\ - Pie diagramming \\ - Card writing and sorting \\ - Matrix ranking and scoring \\ - Linkage diagramming \\ - Pocket voting \\ - Venn diagramming
}

Applications of activities like these are many including numerical comparisons of many sorts. Some of the more common are:

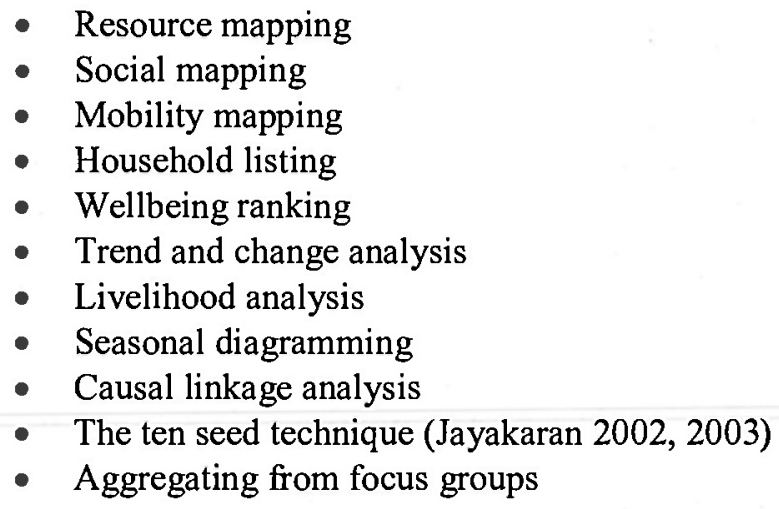

Many illustrations are now accessible ${ }^{\mathrm{xv}}$ in the literature. Much of it is grey though some is beginning to be published in journals that are conventionally regarded as of higher status. On the statistical side, the Statistical Services Centre at Reading University has been in the lead especially with its remarkable pioneering work with partners in Malawi. To give a taste of some of the range, here are some examples of participatory numbers relating to poverty and to pro-poor programmes:

- Mapping and counting in Nepal. The earliest case of a large-scale survey with participatory visual analysis and no questionnaire may have been in 1992 with ActionAid's use of PRArelated methods, mainly mapping, classifying and counting, in over 130 villages in Nepal (ActionAid-Nepal 1992). This was a survey of utilisation of services. It covered the whole 
population in the villages and generated 13 tables similar to those from a questionnaire. The population identified by the mapping summed to 35,414 .

- Pile sorting and coping strategies. An SCF (UK) study in 20 Districts in Malawi, Zambia, and Zimbabwe used pile sorting (subdividing piles of 60 stones or seeds) and other participatory methods for a retrospective study on how individual poor farmers coped with the 1992 drought (Eldridge, 1995, 1998). The resulting tables were similar to those from a questionnaire survey.

- The Bangladesh PPA. The UNDP PPA in Bangladesh convened focus groups of poor urban and rural women and men and facilitated their analysis of their priorities for "doables", practical measures that would make a difference to their lives. These were aggregated by sex and location to produce cumulative prioritized problem indices (cPPIPs) which gave them comparative numerical values. These were presented in histograms. Among the findings were, for example, that the top priority for rural women was work, and for urban women water (UNDP $1996: 68$ ).

- The Participatory Poverty Index in China. Ways are well known, if not always well practised, for enabling people living in poverty to reflect on and express their priorities. A major problem has been to combine this with comparisons of degrees or deprivation of different communities. An ingenious solution has been developed by a team in China. After careful participatory investigations and iterative pilot testing, eight common indicators were identified as representing people's widespread priorities. Using these, a composite Participatory Poverty Index for each community is constructed from poor people's own allocation of priorities. This is done in a manner which gives numerical expression to relative poverty between communities ( $\mathrm{Li}$ et al 2002; Li and Remenyi and others 2004; Remenyi in draft $)^{\mathrm{xv}}$. The method was adopted and required on a vast scale, and perhaps not surprisingly in those circumstances, was transformed by political and bureaucratic influences and reflexes into something different (pers. comm. Joe Remenyi 2005). Nevertheless, this remains a methodological breakthrough with a problem that had seemed intractable.

- Violence in Jamaica, Guatemala and Colombia. Focus groups facilitated to undertake participatory studies of urban violence in Jamaica, Guatemala and Colombia have identified different types of violence, their seriousness, and the importance, positive or negative, of different related institutions. Their findings have been aggregated, including those from Venn diagramming (Moser and Holland 1997; Moser and Mcllwaine 2000, 2001 and 2004) In the Guatemala study this led to a table derived from 176 focus group listings which showed the frequency of mention of 22 different strategies for coping with violence (Moser and Mcllwaine 2001: 140). Contrary to common professional belief, violence categorised as economic was found to be much more widespread than that which was political.

- Voices of the Poor. Aggregation from focus groups was also undertaken in the Voices of the Poor study (Narayan et al 2000) in 23 countries. This involved the views of many hundreds ${ }^{\mathrm{xvil}}$ of discussion groups in some 272 communities on, for example, directions of change in violence against women (ibid: 124-131) and characteristics of institutions (ibid 184 and199-202). The results of these were presented in pie charts and tables.

- The Malawi starter pack study. A participatory study was undertaken in Malawi of the "starter pack" [of seeds, fertiliser etc] programme and of small farmers' ideas of sustainability (Cromwell et al 2001). In each of 30 villages, analysis by 3 focus groups, each bringing together a different category of farmer, included pairwise ranking of the relative importance of 15 indicators of sustainability. The results were combined in a table of mean values across villages by region.

- The Malawi census. When a major debate with pro-poor policy implications arose in Malawi about the size of the rural population as enumerated in the national census, participatory mapping and household listing were undertaken in a carefully selected sample of 54 villages 
and combined with household visits. Extrapolation indicated a population of 11.5 million compared with the census figure of 8.5 (Barahona and Levy 2003). The Government census office was not willing to discuss the discrepancy. In their paper, Barahona and Levy elaborate the statistical principles relevant for rigour in such studies.

- The Malawi Targeted Inputs Programme (TIP) study. An ingenious and sensitive sequence of participatory methods, using community mapping with cards, was devised, tested and applied in Malawi to identify what proportions of those who were food secure, food insecure, and extremely food insecure had received inputs from the TIP programme. The programme was intended for the poor. All of the extremely food insecure should have received the inputs, and none of the food secure. However, the study found that 21 per cent of recipients were food secure, 38.5 percent food insecure, and 40 per cent extremely food insecure, the corresponding figures for non-recipients being 33, 40 and 27 percent respectively (Levy 2003).

- Wealth/well-being ranking ${ }^{x \prime \prime \prime}$. In wealth or more usually wellbeing ranking, household lists are usually derived from participatory social maps, and written on cards which are then sorted into piles, often by several groups which then meet to triangulate, and then explain the criteria implicit in their allocations. In recent years this has been rapidly adopted as a part of insightful poverty-related research. For the May 2004 Toronto Conference $Q$-Squared in Practice: a conference on experiences combining qualitative and quantitative methods in poverty appraisal, 14 papers were selected from over 60 proposed. In the research reported in these 14, 10 had used PRA-type visuals or tangibles, and no less than 8 had used wealth/wellbeing ranking. One of the papers (Hargreaves et al 2004a) described a breakthrough in South Africa with a household wealth index that made comparisons of poverty possible between people in different communities ${ }^{\mathrm{xix}}$.

Given experiences like these, it is sad to see how major organisations like the OED of the World Bank are to such a degree still stuck struggling with old ways, most notably large-scale long questionnaires, of trying to find things out. Given what we now know, this is inefficient. Is it that the larger and more powerful you are, the harder it is to change your ways?

A feature of most of these methods and applications has been time taken to experiment, test and modify them in the field with people in communities, with eclectic borrowing, adaptation and improvisation of methods and sequences in order to assure rigour and a good fit. In the case of the Malawi starter pack study, this was a team activity for an intensive three weeks (pers. comm. Fiona Chambers). In the case of the China PPI it was longer, with iterations. These methods were thus tailor-made and tested for fit. They were not taken off the shelf. Together they give some indication of potential, showing that there can be many alternatives to questionnaires that can lead to better insights and more accurate numbers. ${ }^{\mathrm{xx}}$ Many more no doubt remain to be invented.

Three words of caution are in order. First, the ethical issues of participatory research (as of other research) deserve careful and sensitive attention. Second, the training, behaviour and attitudes of facilitators are critical for good results. This was especially stressed in the South African wealth/wellbeing ranking where training and mentoring of facilitators was intensive and sustained (pers. comm. Anton Simanowitz). Third, given the evidence it is difficult to imagine that approaches like these will not be much more widely adopted, indeed that they are a wave of the future; but experience with other participatory approaches and methods suggests that progress will be slow and accompanied by bad practice. Professional conservatism in bureaucracies, the reproduction of normal professionalism by universities and training institutions, so often the las to learn and change, and inappropriate behaviour and attitudes, can be expected to remain major obstacles. 


\section{Listening, learning and immersions}

For learning about poverty in a participatory mode, the behaviours and attitudes of the contextually powerful -the would-be leamers, whether senior staff, middle management, field facilitators or researchers, have proved more important than the methods used. They include the donts - don't lecture, don't criticise, don't be important, don't dominate, don't rush......and the do's - do be sensitive, respect, sit down, listen, learn, facilitate, take time, be nice to people.... and the like.

Three streams of activity have contributed much here

The first is listening and learning. An outstanding example is Harsh Mander's (2001) book Unheard Voices: stories of forgotten lives. These are accounts of the lives and struggles of people in India "who in many ways, have been pushed to the extreme edges of society...street children, sex workers, women, dalit and tribal survivors of atrocities, riot victims, especially women, homeless and destitute people, scavengers of night soil, and those living with leprosy and HIV" (ibid. ix), and people displaced by big development projects, survivors of famines, and human-made and natural disasters. Some are excruciating to read, and tell of realities and resilience which are beyond normal middle class imaginations. Another is Listening to people living in poverty (Parasuraman et al 2003) based on in-depth reading of over 250 life stories of poor people in Vietnam, Pakistan, Nepal, India and Bangladesh. It presents 29 of these, and then derives basic concepts and a framework from them "in an open-ended structure that is continuously evolving." (ibid. xiv). This, as might be expected, stresses multidimensionality, (for example "depletion of bodily resources": ibid 202), and power relations between poor people and institutions. Institutions are differentiated into discriminatory, contractual and affirmative, and interactions into constructive, nurturing, redistributive, profitable, maintenance, damaging, punitive, depriving and destructive (ibid 206-214).

The second is what are known as immersions or reality checks (Eyben 2004; Irvine et al 2004; IDS Participation Group, 2005). These are direct experiences by development professionals who spend a time, usually a few days and nights, living in poor communities with poor people. Pioneered in an organised form as the Exposure and Dialogue Programme by Karl Osner and others in Germany, practices have been spreading and emerging spontaneously in different forms. Senior managers in the World Bank have had their own programme. Perhaps the best known and most influential immersion or reality check was that of Ravi Kanbur, when he was directing the World Development Report 2000/01 in which part of his account was published (World Bank 2000: 2). The trade union SEWA in India has internalised immersions as part of the induction for new staff, who now spend time living and working with their members. Some staff in the INGO ActionAid International practise immersions for their own learning: in the Western Region of Kenya, all 35 staff members now undertake and experience these reality checks twice a year, resulting in "a huge change in the way we think, the way we work" (pers. comm Ashish Shah August 2005).

The third is so far a one-off, and has not to my knowledge been repeated; but might just be a wave of the future. It is another form of immersion that had remarkable results. In 2002 SDC (the Swiss agency for Development and Cooperation) organised a four-week participatory and qualitative study of 26 poor households, with careful and sensitive training and facilitation. SDC staff spent entire days, from waking to sleeping, and without taking notes - to avoid distraction and so that their hands could be free, living and working with the families. There were striking insights such as how much more important shelter and the quality of housing were to poor people than had been supposed (Jupp et al 2003). For the researchers, the experience proved personally 
and professionally transformational. They reflected, for example "We had no idea what poverty was really like until we were involved in this study" and "I thought I knew about village life as my roots are in the village and I still visit family in my village from time to time. But I know nothing about what it is like to be poor and how hidden this kind of poverty can be" (Jupp 2004: 4 and pers comm). As the trainer and facilitator observed, despite the risks, the outcomes of the exercise were extraordinary.

\section{Participation, Creativity and Pluralism: a pro-poor paradigm?}

A difficulty in writing this paper has been a sense of an explosion of poverty-related participatory activities in recent years. It is hard to judge, and I may be wrong, but I have the impression that we development professionals, especially negative academics, have been so aware of bad practice in the name of participation that we have overlooked the break out of improving and at times brilliant innovative practice ${ }^{\mathrm{xx}}$. It is scattered, and often unconnected, and quite often short-lived. Much of it is by NGO staff and dispersed and isolated in small organisations and countries of the South. Much of it turns standard labelling and branding, central ownership and control, and the ego associated with these, on their heads ${ }^{\mathrm{xx} 11}$. There is a telling example in the history of Reflect. In its early days, after piloting, Reflect had a Mother Manual. But this was quickly abandoned. The idea of a centralised, standardised, detailed right way of doing things was a paradigmatic misfit. It is the principles, not the details of practice, or even the label, that matter. Reflect in Nepal now has 16 different local names, each taking its own form with local ownership and fit (pers. comm. Bimal Phnuyal). Similar isolated creativity and diversity are found with the work of consultants who innovate in a participatory mode. Unfortunately, the very nature of one-off consultancy means that they lack time, sponsorship or even inclination to reflect on, record, share or spread what they have evolved; and those who commissioned their work rarely provide for such activities. Instead they tick the box of satisfactory completion, and move on to other things. Much promising participatory innovation is, thus, isolated or still-born.

Paradigm is not a word to use lightly. Almost anything that looks different is so labelled these days. But in the sense of concepts, ideas, perceptions, values, methods, behaviours and relationships which are mutually supporting and reinforcing, it can be asked whether we have here an emergent paradigm of participation and pluralism, and with it of perceptions of poverty. Participation goes with changing power relations and behaviours, and sharing; pluralism goes with openness, mutual learning, eclectic improvisation and creativity; and perceptions of poverty are both those of professionals and of people living in poverty. In this paradigm, it is the experience, conditions and realities of poor people, and their analysis and expression of these, that come first. For this to happen well, professional unlearning has its part to play. As with PPAs, with sensitive and hidden topics, with nets or webs of disadvantage, with participatory numbers, and with listening, learning and immersions, the primary role of professionals is to convene, facilitate, learn and then later communicate. This is not to undervalue trained professional competences. It is not substituting one fundamentalism for another. It is, rather, correcting an imbalance. It is starting in another place, upending the normal, and empowering those who lack power through enabling them to conduct their own analysis and supporting them It is then that the diversity of deprivations becomes more evident, and the many forms that multidimensional poverty can take. It is then, too, that we may conclude that there is no one final best set of concepts, ideas, perceptions, methods or behaviours, but only continuous mixing, adoption, adaptation, improving, improvising and creativity, energised by commitment and informed by search, practice, doubt, and reflection. Participation and poverty both take many forms. And the potentials for combining them to enhance the wellbeing of those who suffer multiple deprivations have scarcely begun to be tapped. Poverty may never be made history. But we can ask whether a precondition for its sharp reduction is that powerful professionals become 
more participatory and get closer to and learn more from those who live their lives in poverty; and then act on what they experience, learn and feel.

6 August 05

Robert Chambers

r.chambers@ids.ac.uk

\section{References:}

ActionAid-Nepal 1992 Participatory Rural Appraisal Utilisation Survey Report Part 1: Rural Development Area Sindhupalchowk, Monitoring and Evaluation Unit, ActionAid-Nepal P.O.Box 3192, Kathmandu.

Archer, David and Nandago Maria Goreth 2004 "Participation, literacy and empowerment: the continuing evolution of Reflect" Participatory Learning and Action 50: $35-44$

Ashford, Graham and Saleela Patkar 2001 The Positive Path: using appreciative inquiry in rural Indian communities. DFID, IISD and MYRADA

Barahona, Carlos and Sarah Levy 2003 How to generate statistics and Influence Policy Using Participatory Methods in Research: Reflections from Malawi 1999-2002. Working Paper 212, IDS Sussex, November

Beck, Tony 1994 The Experience of Poverty: Fighting for respect and resources in village India Intermediate Technology Publications, London

Booth, D., J. Holland, J. Hentschel, P.Lanjouw, and A. Herbert 1998 Participation and Combined Methods in African Poverty Assessment: renewing the agenda, Report commissioned by DFID for the Working Group on Social Policy, Special Program of Assistance for Africa.

Brock, Karen and Rosemary McGee eds 2002 Knowing Poverty: Critical reflections on participatory research and policy, Earthscan, London and Sterling VA

Chambers, Robert 1997 Whose Reality Counts? Putting the First Last. ITDG Publications, Rugby, UK

Chambers, Robert 2002 "Power, knowledge and policy influence: Reflections on an experience" in Brock and McGee eds Knowing Poverty pp135-165

Chambers, Robert 2003a "Qualitative approaches: self-criticism and what can be gained from quantitative approaches" in Kanbur ed Q-Squared: 22-27

Chambers, Robert 2003b "The Best of Both Worlds", in Kanbur ed Q-Squared: 35-45

Chambers Robert, 2005 Ideas for Development, Earthscan, London and Sterling VA

Cooke, Bill and Uma Kothari eds 2001 Participation: the New Tyranny?. ZED Books, London, New York

Cornwall, Andrea and Alice Welbourn eds 2002 Realizing Rights: Transforming Approaches to Sexual and Reproductive Well-being. ZED Books, London 
CPRC 2005 The Chronic Poverty Report 2004-05. Chronic Poverty Research Centre, Institute for Development Policy and Management, University of Manchester, Manchester UK

Cromwell, E., P.Kambewa, R. Mwanza, and R.Chirwa with KWERA Development Centre 2001 Impact Assessment Using Participatory Approaches: 'Starter Pack' and Sustainable Agriculture in Malawi. Network Paper No 112, Agricultural Research and Extension Network, Overseas Development Institute, London

Education Action 1994 - 2005 continuing twice a year in four languages ActionAid, London www.reflect-action.org

Eldridge, Christopher 1995 Methodological notes, instructions to facilitators, household responses to drought study in Malawi, Zambia, and Zimbabwe, Save the Children, UK

Eldridge, Christopher 1998 Summary of the Main Findings of a PRA Study on the 1992 Drought in Zimbabwe, Save the Children, UK

Eldridge, Christopher 2001 Investigating Change and Relationships in the Livelihoods of the Poor Using an Adaptation of Proportional Piling, Save the Children, UK.

Elliott, Charles 1999 Locating the Energy for Change: An Introduction to Appreciative Inquiry, International Institute for Sustainable Development, Winnipeg, Canada

Estrella, M. with J. Blauert, D. Campilan, J. Gaventa, J. Gonsalves, I.Guijt, D. Johnson, and R. Ricafort eds 2000 Learning from Change: issues and experiences in participatory monitoring and evaluation. Intermediate Technology Publications, London

Eyben, Rosalind 2004 Immersions for Policy and Personal Change. IDS Policy Briefing Issue 22, IDS Sussex, UK July

Francke, M 2003 "Including the poor excluded people of Ayacucho in the construction of the "truth": Reflections on methods and processes for the realisation of rights", unpublished paper available from mfrancke@pucp.edu.pe

Gibson, Tony 1996 The Power in Our Hands Neighbourhood based - World shaking, Jon Carpenter, Carlbury, Oxfordshire, UK

Hammond, Sue Annis and Cathy Royal eds 1998 Lessons from the Field: applying appreciative inquiry, Practical Press Inc, Plano, Texas

Guijt, Irene and Laurens van Veldhuizen 1998 What Tools? Which Steps? Comparing PRA and PTD. IIED Issue paper no 79, International Institute for Environment and Evelopment, London, December

Guijt, Irene 2000 'Methodological issues in participatory monitoring and evaluation'. In Estrella with others eds Learning from Change pp 201-216.

Hargreaves, James R, Linda Morison, John S.S Gear, John D.H.Porter, Mzamani B Makhubele, Julia C. Kim, Joanna Buzsa, Charlotte Watts, and Paul M Pronyk 2004a "Hearing the voices of the poor": Assigning poverty lines on the basis of local perceptions of poverty: 
a quantitative analysis of qualitative data from participatory wealth ranking in rural South Africa", paper presented to Q-Squared in Practice: a conference on experiences combining qualitative and quantitative methods in poverty appraisal, Toronto 15-16 May 2004 [correspondence as below]

Hargreaves, James R, Linda Morison, John S.S Gear, John D.H.Porter, Mzamani B Makhubele, Julia C. Kim, Charlotte Watts, and Paul M Pronyk 2004b The assessment of household wealth in health studies in developing countries; a comparison of participatory wealth ranking and survey techniques from South Africa, typescript [correspondence to James Hargreaves, Clinical Research Unit, London School of Hygiene and Tropical medicine, Keppel St, London WC1E 7HT email jimharg@soft.co.za ]

Hartmann, Betsy and James Boyce 1983 A Quiet Violence: View from a Bangladesh Village. Zed Press, London

Haverkort, Bertus, Johan van der Kamp and Ann Waters-Bayer 1991 Joining Farmers' Experiments: Experiences in Participatory Technology Development. Intermediate Technology Publications, London

Hickey, Samuel and Giles Mohan eds 2004 Participation: from tyranny to transformation? ZEDBooks, London and New York

Holland, Jeremy with James Blackburn eds 1998 Whose Voice? Participatory research and policy change. IT Publications, London

IDS Participation Group 2005 Immersions and Reality Checks, source materials, available from Jane Stevens, Participation Group, Institute of Development Studies, Sussex BN1 9RE, UK i.stevens@,ids.ac.uk

International HIV/AIDS Alliance 2003 Developing HIV/AIDS Work with Drug Users: a guide to participatory assessment and response, International HIV/AIDS Alliance, Brighton UK

Irvine, Renwick, Robert Chambers and Rosalind Eyben 2004 Learning from poor people's experience: immersions. Lessons for Change in Policy and Organisations No 13, IDS Sussex, UK

Jayakaran, Ravi .2002 The Ten Seed Technique, World Vision, China. ravi iayakaran@wvi.org

Jayakaran, Ravi 2003 Participatory Poverty Alleviation and Development, a comprehensive manual for development professionals. World Vision, China. ravi_jayakaran@wvi.org

Joseph, Sam 2005 Rwanda Ubudehe: Local Collective Action, update June 2005, Kigali, Rwanda

Jupp, Dee 2003 Views of the Poor: the perspective of rural and urban poor in Tanzania as recounted through their stories and pictures, Swiss Agency for Development and Cooperation, Berne, May

Jupp, Dee 2004 "Views of the Poor: Some thoughts on how to involve your own staff to conduct quick, low cost but insightful research into poor people's perspectives" available on request from diupp@tiscali.co.uk 
Kanbur, Ravi 2000 "Basrabai's story" in World Bank 2000 Attacking Poverty: 2

Kanbur, R. ed. 2003 O-Squared: qualitative and guantitative methods of poverty appraisal, Permanent Black, D-28 Oxford Apartments, 11, I.P. Extension, Delhi 110092

Kane, Liam 2001 Popular Education and Social Change in Latin America, Latin America Bureau, 1 Amwell Street, London EC1R 1UL

Kar, Kamal 2003 Subsidy or Self-respect? Participatory Total Community Sanitation in Bangladesh, Working Paper 184, IDS Sussex UK

Levy, Sarah 2003 "Are we targeting the poor? Lessons from Malawi”, PLA Notes 47: 19-24

Li, Xiaoyun et al 2002 Preparing a Methodology for Development Planning in Poverty Alleviation under the New Poverty Strategy of PRC, ADB/TA3610-PRC, Asian Development Bank, Manila

Li, Xiaoyun and Joe Remenyi, LiZhou, Wang Sibin, Zhang Chuntai,Liu Yonggong 2004 Who's Poverty? Making Poverty Mapping and Monitoring Participatory, typescript, College of Humanities and Development, China Agricultural University

MacGillivray, A., C. Weston, and C. Unsworth 1998 Communities Count! a step by step guide to community sustainability indicators. New Economics Foundation, London

Mander, Harsh 2001 Unheard Voices: stories of forgotten lives, Penguin Books, New Delhi, London, New York, Victoria, Toronto, Auckland

Marsland, N., I.M.Wilson, S. Abeyasekera and U.K. Kleih 2000 A methodological framework for combining quantitative and qualitative survey methods. Statistical Guide. Statistical Services Centre, University of Reading, Reading UK www.reading.ac.uk/ssc

May, Julian, with Heidi Attwood, Peter Ewang, Francie Lund, Andy Norton and Wilfred Wentzal 1998 Experience and Perceptions of Poverty in South Africa. Final Report of the South African PPA, Praxis Publishing, Durban

Mayoux, Linda and Robert Chambers 2005 "Reversing the Paradigm: Quantification, participatory methods and pro-poor impact assessment", Journal of International Development, 17, 271-298

McCarthy, Julie with Karla Galvao 2004 Enacting Participatory Development: Theatre-based techniques a resource for theatre and participatory development. Earthscan, London and Sterling VA

McGee, Rosemary, with Josh Levene and Alexandra Hughes 2002 Assessing Participation in Poverty Reduction Strategy Papers: a desk-based synthesis of experience in Sub-Saharan Africa. IDS Research Report 52, IDS Sussex, February

Moser, C. and J. Holland 1997 Urban Poverty and Violence in Jamaica, World Bank Latin American and Caribbean Studies Viewpoints. Washington DC: World Bank. 
Moser, C.and C. Mcllwaine. 2000 Urban Poor Perceptions of Violence and Exclusion in Colombia. Latin American and Caribbean Region, Environmentally and Socially Sustainable Development Sector Management Unit. Washington DC: World Bank.

Moser, C. and C. Mcllwaine 2001 Violence in a Post-Conflict World: Urban Poor Perceptions from Guatemala, Latin America and Caribbean Region, Environmentally and Socially Sustainable Development Sector Management Unit. Washington DC: World Bank.

Moser, Caroline and Cathy Mcllwaine 2004 Encounters with Violence in Latin America: Urban poor perceptions from Colombia and Guatemala. Routledge, New York and London

Mukherjee, Neela. 1995 Participatory Rural Appraisal and Questionnaire Survey: Comparative Field Experience and Methodological Innovations. Concept Publishing Company, A/15 16, Commercial Block, Mohan Garden, New Delhi 110059.

Mukherjee, Neela 2001 Participatory Learning and Action - with 100 field methods. Concept Publishing Company, A/15-16, Commercial Block, Mohan Garden New Delhi 110059.

Narayan, Deepa, Robert Chambers, Meera K. Shah and Patti Petesch 2000 Voices of the Poor: Crying Out for Change, Oxford University Press for the World Bank

Parasuraman, S., Gomathy, Kumaran Raj and Bina Fernandez 2003 Listening to people living in poverty. Books for Change, 139 Richmond Road, Bangalore 560025 www.booksforchange.net

PLA Notes (formerly RRA Notes, and now Participatory Learning and Action), triannual, International Institute for Environment and Development, 3 Endsleigh Street, London WC1H ODD. Email sustag(iied.org Website www.iied.org

PRA Report Video c 1993 Video by World Vision, Australia, of a PRA Training in Zambia

PRAXIS 2001 The Politics of Poverty: a tale of the living dead in Bolangir, Books for Change. Bangalore

Reason, Peter and Hilary Bradbury eds 2001 Handbook of Action Research: Participative Inquiry and Practice, Sage Publications, London, Thousand Oaks, New Delhi

Remenyi, Joe 2005 (in draft) Poverty Analysis, Poverty Mapping and Participation in China, paper from Writeshop on Creating and Evolving Participatory Methodologies, IDS Sussex

Robb, Caroline 2002 Can the Poor Influence Policy? Participatory Poverty Assessments in the Developing World. The World Bank and International Monetary Fund, Washington DC

RRA Notes 15 (1992) Special Issue on Applications of Wealth Ranking. International Institute for Environment and Development, London

Scarry, E. 1985 The Body in Pain, the Making and Unmaking of the World, Oxford University Press, New York [cited in Parasuraman et al]

Sen, Amartya 1999 Development as Freedom, Oxford University Press 
Shah, M. Kaul (1999) 'A Step-by step guide to popular PLA tools and techniques'. Chapter 2 in Shah et al eds Embracing Participation in Development

Shah, M. Kaul S. Degnan Kambou and B.Monahan, B. eds 1999 Embracing Participation in Development: worldwide experience from CARE's reproductive health programs, USA: CARE, 151 Ellis Street, Atlanta, Georgia 30303.

Simanowitz, A and B. Nkuna 1998 Participatory Wealth Ranking Operational Manual, Small Enterprise Foundation, Tzaneen, South Africa [contact a.simanowitz@ids.ac.uk]

Simanowitz, A., B. Nkuna and S. Kasim 2000 Overcoming the obstacles to identifying the poorest families, unpublished report [contact a.simanowitz@ids.ac.uk]

UNDP, Bangladesh 1996 UNDP's 1996 Report on Human Development in Bangladesh. Volume 3 Poor people's perspectives, UNDP, Dhaka

Welbourn, Alice 1995 Stepping Stones: a training package on gender, HIV, communication and relationship skills. Manual and video, Strategies for Hope, ActionAid, London

Welbourn, Alice 2002 "Gender, sex and HIV: how to address issues that no one wants to hear about", in Cornwall and Welbourn eds Realizing Rights pp 99-112

World Bank 2000 Attacking Poverty. World Development Report 2000/01, Oxford University Press for the World Bank

\section{[ends]}

${ }^{i} I$ recognise that many usages are possible. In another context I used deprivation to encompass more than poverty. Poverty was "a condition of lack of physical necessities, assets and income. It includes, but is more than, income-poverty. Poverty can be distinguished from other dimensions of deprivation".

Deprivation was "lacking what is needed for well-being. Deprivation has dimensions which are physical, social, economic, political and psychological/spiritual. It includes forms of disadvantage such as social inferiority, physical weakness, isolation, poverty, vulnerability, powerlessness and humiliation" (Chambers 1997: xiv, xv)

"Some sources, most of which include many references to others, are: Reason and Bradbury 2001 for participatory action research; PLA Notes and Chambers 1997 for PRA and PLA; Haverkort, van der Kamp and Waters-Bayer 1991 and Guijt and van Veldhuizen 1998 for Participatory Technology Development; Hammond and Royal 1998, Elliott 1999, and Ashford and Patkar 2001 for Appreciative Inquiry; Gibson 1996 for Planning for Real; Kane 2001 for popular education; Education Action and Archer and Goreth 2004 for Reflect; McCarthy and Galvao c.2001 for popular theatre; and McGillivray et al 1998, Estrella et al 2000 and Guijt 2000 for PM and E. For a recent review across a range of approaches and applications see Participatory Learning and Action (formerly PLA Notes) 50 Critical reflections, future directions. IIED, London

${ }^{i i}$ For PPAs see Holland with Blackburn 1998 for accounts and analysis of Ghana, Zambia, South Africa and Mozambique; and Norton 2001 and Robb 2002 for authoritative reviews.

${ }^{1 v}$ For example, a group of seven school girls in M'tendere Comp;ound, Lusaka, matrix scored a typology of

sex partners and preferences, with 16 categories of male partners scored against 5 criteria (Shah 1999:52)

${ }^{v}$ For the Internal Learning System see chapters by Nagasundari, Narendranath and Noponen in a book in

preparation edited by Karen Brock k.brock@in4action.com and Jethro Pettit j.pettit@ids.ac.uk

${ }^{v 1}$ For a self-critical review of the process see Chambers 2002 
vii For a more extended analysis of the origins and process of developing these diagrams, see Chambers 2002: $147-8$

vil For more on the multiple adverse interactions of tropical seasonality for poor people see Robert Chambers, Richard Longhurst and Arnold Pacey eds 1981 Seasonal Dimensions to Rural Poverty. Frances Pinter, London (out of print). For an out-of-date update see Chapter 4 in my book Challenging the Professions. Intermediate Technology Publications, 1993, which also has a short bibliography. This remains an astonishingly neglected subject despite its phenomenal policy implications.

ix This is not to suggest at all that this is a new insight. For the UK, for example, see Friedrich Engels The Conditions of the Working Class in England (1845) and Charles Dickens Hard Times (1854). The question is whether the multiple interactions of disadvantage which have spatial dimensions have been adequately appreciated by professionals.

${ }^{x}$ The authors refer at the end of this paragraph to Scarry 1985 , but these conclusions flow too from their own analysis.

${ }^{\mathbf{x l}}$ This was a repeated complaint in focus groups in the Voices of the Poor study (Narayan et al 2000:

chapter 5)

xii For an attempt to summarise the benefits of quantification see Chambers 2003a

xili For an early comparison with questionnaire approaches see Mukherjee 1995.

${ }^{\text {xiv }}$ For an overview and sources in mid 2003, see Robert Chambers "Participation and Numbers", PLA

Notes 47, August 2003: 6-12, itself a revision and update of Chambers 2003a "The Best of Both Worlds" in Kanbur ed Q-Squared, 2003: 35-45. See also Mayoux and Chambers 2005. These articles present more

evidence and reference more sources that this current paper which, however, includes some new material.

${ }^{\mathrm{xv}} \mathrm{A}$ rich source is the jourmal PLA Notes now Participatory Learning and Action. Other sources include

the websites of the Statistical Services Centre at Reading University www.reading.ac.uk/ssc and of the

Participation Group at the University of Sussex www.ids.ac.uk/ids/particip See also Mukherjee 2001.

${ }^{x v 1}$ The method is described in the sources. It would take too much space to describe it here

xvi A precise figure cannot be given for two reasons: the total number of discussion groups was not recorded for every country though it was probably over 1,500 (Narayan et al 2000: 298-305); and not all discussion groups produced relevant comparable data suitable for analysis.

${ }^{\text {xvil }}$ For an early treatment of wealth/wellbeing ranking see RRA Notes 15 Special Issue on Applications of Wealth Ranking. IIED, London, 1992

${ }^{x i x}$ See also Hargreaves et al 2004b. The Hargreaves et al sources also refer to Simanowitz and Nkuna 1998 and 2000

${ }^{\mathrm{xx}} \mathrm{My}$ assertion of accuracy would need a further paper. I would be delighted to discuss this with anyone who is interested. Earlier evidence was in my book Whose Reality Counts? chapters 6 and 7

${ }^{x \times i}$ For example the Cooke and Kothari eds book Participation: the New Tyranny? (2001) focused on bad practices and drew attention away from evolving good practice and potentials, now however more recognised in its successor Hickey and Mohan eds Participation: from Tyranny to Transformation? (2004) ${ }^{x x i i}$ For a review of branding, ownership and ego in participatory methodologies, see Bimal Phnuyal, contribution in preparation, for Brock and Pettit eds in preparation. 


\section{Participation, Pluralism and Perceptions of Poverty}

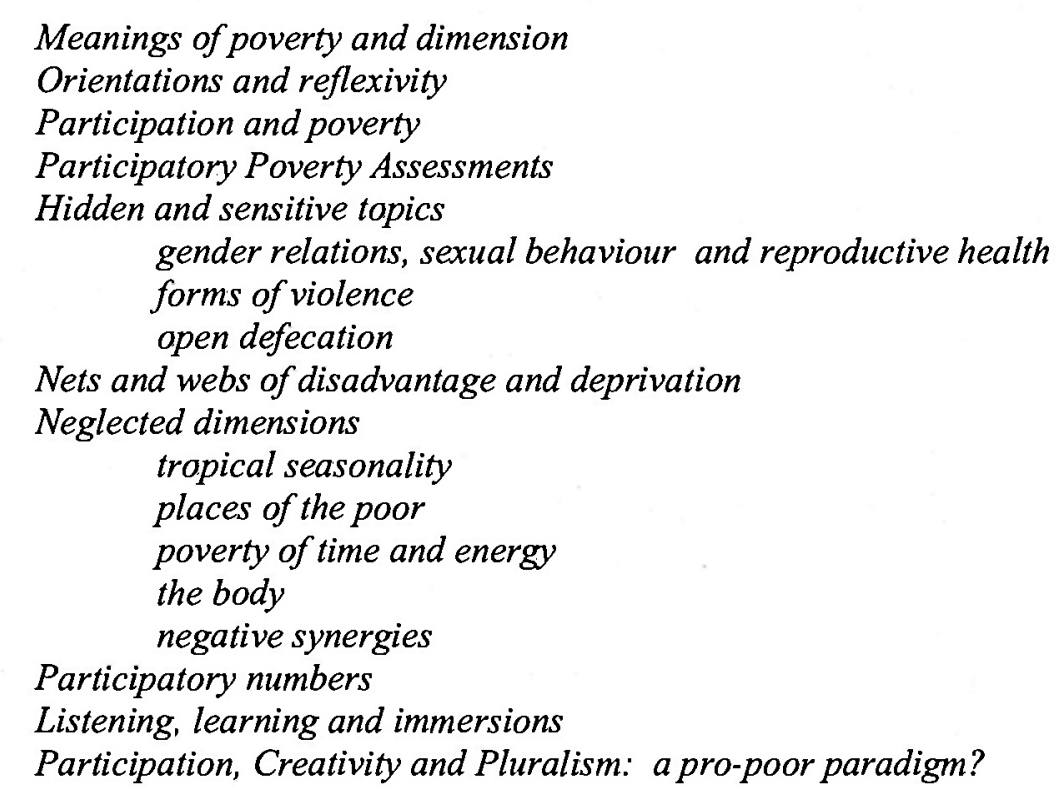

"The promise of both participatory research and the focus on well-being is that they will enable us to hear genuinely different voices, voices that speak from and about realities other than those configured by development discourse and institutions" (White and Pettit 2004:95)

\section{Meanings of poverty and dimension}

Both poverty and dimension are words used with many meanings. In this chapter, the meanings given to them are as follows.

Poverty includes bad condition and/or experience of life. This is more than material poverty or lack. It is the meaning implied by the statement with which the World Development Report (WDR) 2000/01 Attacking Poverty opens "Poverty is pronounced deprivation in wellbeing" (World Bank 2000: 15). "Multidimensional poverty" is then the same as "multidimensional deprivation".' Well-being is the experience of good quality of life, and ill-being, its opposite, the experience of bad quality of life. This applies especially where material and other deprivations and disadvantages interact and reinforce each other (see nets and webs below).

Dimension. In the literature this is used in at least three senses.

First, the Research Group on Wellbeing in Developing Countries at the University of Bath (White and Pettit forthcoming) describes three dimensions of wellbeing, and by implication of its opposites, illbeing, poverty or deprivation. These are subjective, objective, and interactive or process. Subjective can be taken to mean what is experienced, objective to refer to conditions or causes outside a person, and interactive or process to encompass how subjective (internal and experiential) and objective (external) affect each other. 
A second sense of dimension is that in the WDR 2000/2001 (see e.g. v, 1, 15 and passim) which "sets out actions to create a world free of poverty in all its dimensions". The multiple deprivations listed in the Report, besides low income or consumption, include lack of education, health, food and shelter, fear, powerlessness and voicelessness. And the WDR says that there is "a powerful case for bringing vulnerability and its management to center stage" (ibid 32). The WDR implicitly separates some of the more experiential dimensions of poverty from their determinants (e.g. ibid:34).

A third and broader usage includes the first two and extends dimension to include causes to a greater extent. Thus, for example, "Corrupt and arbitrary governance constitutes a significant factor that defines and contributes to the various other dimensions of poverty" (Parasuraman et al 2003: 33 my emphasis). This was also the sense which evolved out of the Voices of the Poor process, in which participatory approaches and methods were used to enable poor people in close to 300 communities in 23 countries to express and analyse their realities (Narayan et al 2000). After stating that "The dimensions of deprivation are multiple", ten "Dimensions of Powerlessness and Illbeing" were elicited and described:

$\begin{array}{ll}\text { Capabilities: } & \text { lack of information, education, skills, conffide } \\ \text { Livelihoods and assets: } & \text { precarious, seasonal, inadequate } \\ \text { Places: } & \text { isolated, risky, unserviced, stigmatised } \\ \text { The body: } & \text { hungry, exhausted, sick, poor appearance } \\ \text { Gender relations: } & \text { troubled and unequal } \\ \text { Social relations: } & \text { discriminating and isolating } \\ \text { Security: } & \text { lack of protection and peace of mind } \\ \text { Behaviours: } & \text { disregard and abuse by the more powerful } \\ \text { Institutions: } & \text { disempowering and excluding } \\ \text { Organizations of the poor: weak and disconnected }\end{array}$

(Narayan et al 2000: 248-9 and figure 2 below)

Many dimensions can thus be identified. As in other chapters in this book, they may be physical, material, economic, social, psychological, institutional, or legal, or related to capability, power or vulnerability. They may be experiential (or subjective), external to a person (or objective), related to interaction, process or cause. They may be combinations of any of these. To be open to the many realities and meanings of those who experience deprivations, there is little gain and perhaps some loss in any exclusive definition of dimension. I therefore allow the span of this chapter to cover these various and several senses, relying on other words and context to indicate particular meaning.

\section{Orientations and Reflexivity}

We have travelled far in professional views of poverty. It is striking how the reductionist moneymetric view of poverty has been, and to some extent remains, disproportionately dominant in much development discourse. For some economists and others it is a bedrock; for others, a default mode. Reviewing the important debates on poverty and the poverty line in India Tony Beck observed (1993: 16) that "..the central preoccupation of the majority of authors on poverty has been the accuracy of the statistics and the statistical techniques used". A tempting caricature of the concept of poverty implied by such debates could be of a top-down, centre-outwards, ivory tower, mathematical construct, overfed and driven by questionnaires, statistics, computers, regressions, equations, graphs and tables. In this view, it could be seen as sustained by erudite, incestuous and self-reproducing systems of high status organisations and departments, and by teaching, textbooks, international conferences, prestigious journals and rigorous professional peer 
review. Economists, it might be suggested, construct their own reality of poverty based on reported income or consumption, provoking the verse:

\section{Economists have come to feel \\ What can't be measured isn't real \\ The truth is always an amount \\ Count numbers, only numbers count}

But those, like myself, who enjoy writing this sort of stuff about economists, have to look at ourselves. We too find it useful and indeed necessary to refer to poverty lines; and their accuracy, what they represent, and the distributions and trends they suggest, do matter. All of us development professionals have our biases and predispositions. Arguably, any writing on development should be preceded by a reflexive paragraph outlining those of which the author is aware. Let me list some of mine. As a lapsed biologist and historian, and now undisciplined social scientist, I take pleasure, and have sustained a livelihood, by looking for gaps between professions and aspects of realities that seem to have been overlooked or understudied. I recognise that I am liable to exaggerate the importance of such gaps, and am vulnerable to glee when I believe I have discovered a misperception of "normal" professionalism and professionals. In my view, numbers and statistics are important, but often more flawed than their users recognise. I tend to privilege the knowledge, values and abilities of poor and excluded people over those of established groups, especially academics and powerful old men. I have been repeatedly astonished at the insights and capabilities that have been revealed by participatory behaviours, attitudes, approaches and methods. So about these of my predispositions and biases at least (and there are surely others) readers have now been alerted and warned.

\section{Participation and Poverty}

In the past decade and a half we have come a long way in the invention, evolution and spread of participatory approaches and methods and their contributions to understanding poverty. A new pluralism of methodology and perception has opened up. A thousand flowers have bloomed. At the same time, many have turned into weeds, notably when spread by big bureaucracies. In parallel, though, there have been innumerable examples of good practice. Sourcebooks, guides and manuals of participatory practice have proliferated, and have then increasingly been superseded by eclectic creativity. Participatory methodologies capable of contributing to understanding poverty, and which have become best known and most widespread include: varied forms of participatory action research like cooperative inquiry (Reason and Bradbury 2001); PRA (originally participatory rural appraisal, now often participatory reflection and action) and the more inclusive PLA (Participatory Learning and Action) (Chambers 1997); Popular Theatre (Mda 1983); Reflect (Education Action; Archer and Newman 2003; Archer and Goreth 2004); and many forms of Participatory Monitoring and Evaluation (PM and E)( McGillivray et al 1998 , Estrella et al 2000 and Guijt 2000 ). Well facilitated these to varying degrees can enable and empower poor and marginalised people to conduct and learn from their own analyses, express their values and priorities, and provide insights into dimensions of poverty.

Five clusters of related innovation and insight stand out:

Participatory Poverty Assessments

Hidden and sensitive topics

Nets and webs of disadvantage and deprivation

Participatory numbers

Listening, learning and immersions 


\section{Participatory Poverty Assessments"}

Participatory Poverty Assessments (PPAs) evolved in the early 1990s, notably in Ghana (1993-4), Zambia (1993-) and South Africa (1995- ) and have since become widespread.. By 2002 more than 60 countries had undertaken PPAs with assistance from the World Bank, with a similar number supported by other agencies (Robb 2002: 3). Increasingly PPA-type studies have been carried out at subnational levels, for example in Bolangir District in Orissa, India (PRAXIS 2001). Including all these, PPAs now number hundreds.

A PPA was described in The Rough Guide to PPAs (Norton et al 2001: 6) as "an instrument for including poor people's views in the analysis of poverty and the formulation of strategies to reduce it through public policy". In many of these, focus groups have been combined with PRA methods of analysis. Groups have been facilitated to create and analyse their realities often using visuals and tangibles for methods such as participatory mapping, preference ranking, matrix scoring, Venn diagramming, wealth or wellbeing ranking, and many others. They have covered many aspects of life and experience such as poor people's priorities, access and institutions, gender relations, causal linkages, seasonal variations, and trends and changes.

Repeatedly, PPAs have opened up aspects of poverty which had been relatively overlooked or given inadequate priority. Reviews of PPAs (Booth et al 1998: 5-7) found that they highlighted:

- A sense of isolation, from services, markets, government institutions and information, with physical isolation a key factor

- The key importance of water supplies

- Security of life and livelihood as a primary concern

- Access to curative health as a consistently high priority

- Local visions of poverty relating to prevailing community norms

- Differential vulnerability according to inherent or socially constructed characteristics of individuals (gender, age, childlessness, health status, disability and individual pathologies such as drunkenness)

- Hunger and dietary inadequacy as a distinct dimension of deprivation

- The seasonality of access and vulnerability

- Intra-household poverty dynamics

- The decline of traditional, and insufficiency of alternative, safety nets

- Community-level poverty versus household or individual poverty

Caroline Robb concluded her review of PPAs (second edition, 2002: 104-5)

"The moral imperative for giving the poor a voice in the poverty debate is self-evident The bonus is that engaging with the poor also leads to better technical diagnosis of problems and implementation of solutions. Through PPAs, the poor deepen our understanding of poverty and can influence policymaking. This new approach challenges traditional power relations... when undertaken in an environment of increased trust, PPAs can present opportunities for a more open dialogue and greater understanding between the powerless and those in power."

The processes for Poverty Reduction Strategy Papers (PRSPs) which have superseded PPAs in prominence have been criticised for inadequate consultation. Some, however, have drawn on PPAs, a clear example being Uganda where "the PPA predated the PRSP concept, but was used extensively in revising the national strategy, which became the PRSP" (McGee et al 2002: 8). In 
a remarkable evolution in Rwanda, a PPA process, ubudehe, has been developed and spread in which each commune conducts its own PPA leading to direct local learning and collective action. This process, with trained facilitators, is anticipated to have covered the whole country by the end of 2005 (Joseph 2005). Some PPAs have had a transformative learning impact through involving Government and other staff in the fieldwork with poor communities and people. PPAs have indeed taken many forms and have many continuing potentials for informing pro-poor policy and practice.

\section{Hidden and Sensitive Dimensions}

Participatory methods, creatively evolved and carefully facilitated, have opened up aspects of life which have usually been thought too private, sensitive or dangerous to make public or to analyse. An early example (see also below) was wealth or wellbeing ranking, in which members of a community typically first draw a social map showing all households, then list these on cards, and then sort them into piles according to degrees of wealth or more usually some concept of wellbeing. Middle class urban professionals often regard this as either impossible, or unethical, supposing it will be demeaning and humiliating for those who are worse off. These fears have repeatedly proved unfounded. Three other areas are gender relations and sexual and reproductive wellbeing, violence, insecurity and social abuses, and open defecation.

The first example is the related areas of gender relations, sexual behaviour and sexual and reproductive well-being. Participatory approaches and methods have proved potent in bringing these into the open, and empowering women to take action. Gender relations, and how they have been changing, were a major theme in the Voices of the Poor study (Narayan et al 2000 chapter 6 pp 109-132). Much has been explored and documented as never before in Realizing Rights. transforming approaches to sexual and reproductive well-being (Cornwall and Welbourn 2002). The lives and realities of those who are marginalised, despised, excluded and ignored have been brought out into the light. Sex workers, for example, come to life as people like other people, for whom respect, security and good relations matter as much, if not more, than they do for others. Participatory approaches to HIV/AIDS, especially through the group processes known as Stepping Stones (Welbourne 1995, 2002) have brought what was hidden or unspoken into the open, with frank talk about sex and death, concern for sensitive behaviour and relationships, acceptance of HIV-positive women and men, and counselling and care for the sick and dying. Participatory approaches and methods have also been developed for HIV/AIDS work with drug users (International HIV/AIDS Alliance 2003). Other areas are the sexual behaviours and preferences of adolescents ${ }^{\text {III }}$ and of prepubescent children (unknown to their parents).

The second area is violence, physical insecurity and social abuses. Participatory studies of violence in Jamaica, Guatemala and Colombia have broken new ground, revealing wide differences between beliefs of policy-makers about forms of violence and the realities experienced by ordinary people (Moser and Mcllwaine 2004). In Peru, participatory time lines, matrices and maps were used in Ayacucho as part of the Colectivo Yuyarisu ('We remember') process of the Truth Commission (Comision de la Verdad y Justicia): using these methods, over 100 groups recollected and reconstructed human rights violations which had taken place in the era of political violence 1980-94 (Francke 2003 and pers comm). In many contexts, domestic abuse and violence against women has been brought out into the open. An early example was an allwomen's PRA activity in Tamil Nadu in 1990 (pers. comms. Sheelu Francis and John Devavaram) in which women mapped households and marked with a yellow circle those where the husband was a drunkard. The Voices of the Poor study included perceived prevalence and trends of domestic violence against women. Another illustration is the Internal Learning System introduced into parts of India ${ }^{\mathrm{l}}$. Women individually and in groups keep visual diaries which they 
update every six months. In these they score from 1 to 5 for aspects of quality of life such husbands drinking, domestic violence, Dalits having to drink out of separate glasses, Dalits being made to carry dead bodies or dead animals, and whether a girl can select her life partner. (pers. comms. Vimalanathan, S. Nagasundari and H. Noponen).

A third example is open defecation, widespread in South and Southeast Asia and a major source of sickness, mortality and illbeing for women who lack access to the privacy of a latrine. They are subject to gross gender discrimination being compelled by custom, unlike men, to defaecate unseen. Without latrines this means only before dawn or after nightfall. New participatory approaches are now enabling communities to confront and face the realities, often spurring them into action (Kar 2003, Kar and Pasteur 2005). Community members are facilitated to make defaecation maps, walk transects, inspect the defaecation areas, confront the reality, draw flow diagrams, calculate the cartloads produced and the amounts ingested, and then encouraged to take action on their own. The communities in South Asia that have proudly declared themselves open defecation free now number thousands. The gains in well-being for women is suggested by an inscription on a wall in a totally sanitised village in Maharashtra: 'Daughters from our village are not married to villages where open defecation is practised'. In rural South Asia, where open defaecation is widespread, the scale of potential gains in health, reduced mortality, and wellbeing for millions of women, children and men is so vast that it is difficult to grasp.

The importance of opening up these subjects can scarcely be exaggerated. When they are not surfaced, analysed and confronted, much avoidable illbeing persists. Conversely, the potential for enhanced well-being from improving sexual and gender relations, from tackling and reducing or eliminating violence in its many forms, and from ending open defecation with gains in health and especially for the well-being especially for women and children but also for men - each of these can only be described as phenomenal. Participatory approaches and methods, well facilitated, cannot solve these alone; but there is enough evidence now to realise that they can establish bridgeheads with the possibility of becoming transformative movements which spread on their own.

\section{Nets and webs of disadvantage and deprivation}

We now come to the issue of the multiplicity of dimensions of poverty. When dimension is used in the inclusive sense of this paper, it includes many aspects of disadvantage. In the analysis of the Voices of the Poor study we faced difficult practical issues of how to analyse a large amount of data, most of it qualitative, but some also (see below, next section) amenable to aggregation and quantification. We were continually impressed by how the dimensions of deprivation which emerged from the participatory data were interlinked, and we increasingly saw these links as a net or web in which poor people were trapped. Two diagrams were published (figures 1 and 2). ${ }^{\text {ii }}$ And two others were not (figures 3 and 4).

Figure 1, Development as good change: From illbeing to wellbeing, named five composite dimensions of illbeing and wellbeing, and their interlinkages. Development could be seen as shifting from illbeing to wellbeing with equity, with interventions to enhance wellbeing possible at any of the five points

[figure 1 about here]

Figure 2, Dimensions of powerlessness and illbeing, expanded the circles to ten As the diagram indicates, each of these in turn can take various forms. They combine in powerlessness symbolised by the net. 
[figure 2 about here]

By specifying these characteristics of disadvantage, figure 2 again raises an agenda for intervention with any one of them, and questions of how they interlink and reinforce each other. In any story of the life of a poor person, linkages can be traced.

The versatility and power of these ways of presenting multiple dimensions and causal links can also be illustrated with two further diagrams.

Figure 3, also inspired by the Voices experience (and in part shown in Narayan et al 2000: 97) shows two body syndromes. These express several ways in which a weak, hungry, exhausted body can be part of self-reinforcing syndrome, including reducing the power to bargain, and how less money can mean delayed and lower quality medical treatment. These were both aspects of disadvantage which the Voices evidence presented.

[figure 3 about here]

Figure 4 goes further in complexity. However, all 13 of these dimensions

- material lack

- vulnerability and insecurities

- bad social relations

- physical weakness - the body, exhaustion

- location - places of the poor

- poverty of time

- seasonal dimensions

- capabilities

- disregard and abuse by the more powerful

- ascribed and legal inferiority

- lack of information

- lack of access to services

- lack of political clout

have been articulated and diagrammed by poor people, using variations and combinations of mapping, listing, Venn diagrams, pie diagrams, pile sorting, matrix scoring, pairwise ranking, time lines and seasonal diagrams, wealth and wellbeing ranking and sorting. The web has proved versatile, having been filled out for particular aspects: for sexuality by Susan Jolly (ref) and for transgender and HIV/AIDS by Giuseppe Campuzano (ref).

These webs, especially the last, raise analytical and practical questions. We can ask which aspects and which linkages are found and function for any person, group or set of conditions. If we simplify by conflating or cutting out dimensions, do we risk failing to identify crucial disadvantages or connections? As the diagram indicates, each of the 13 can take various forms. We can also ask whether figures 2 and 4 overstress the negative, in ways in which figures 1 and 3 do not because the latter indicate the potential for transitions (though, of course, these can go either way).

A question remains: whose analysis and categories are to be privileged? These are largely "ours", those of professionals who are not ourselves poor, expressed in "our" language. The words, concepts, categories and priorities of poor people, especially illustrated by the way they 
were elicited and expressed in the Voices of the Poor, were rich and varied, but with commonalities. There are trade-offs to be puzzled over: between "their" realities and ours; between local participatory diversity and commensurability for aggregation; and between many categories representing poor people's realities and fewer categories more manageable for outsider professionals and for measurement.

\section{Four neglected dimensions}

Four dimensions have been so relatively neglected in the professional literature of which I am aware, that I will touch on them here.

\section{Tropical seasonality.}

The interacting seasonal disadvantages include: ${ }^{\mathrm{vII}}$

- hard work in cultivation

- sickness (malaria, Dengue fever, diarrhoeas, skin sores and diseases, snake bite, Guinea worm disease.

- lack of food. The hungry season

- poor quality and rapidly contaminated food.

- physical weakness and exhaustion from combinations of the above

- shortage of money, loans in kind with high implicit interest rates

- isolation, with difficult or no access to markets and medical treatment

- late pregnancy and childbirth

- shelter and housing collapsing, leaking, flooded

- being wet and cold

- the high opportunity cost of not being able to work

- neglect and exposure of children

Season-proofed as they are against all of these, professionals living in urban centres underperceive the multiple interactions of disadvantage for poor people living in rural areas during tropical rains, especially those areas which are "remote". During the rains, travel is often restricted to tarmac roads. Those off the tarmac and especially those "cut off" during the rains, are not visited, met or heard.

\section{Places of the poor.}

A whole chapter in Voices of the Poor (Narayan et al 2000: 71-88) came to be concerned with the places where poor people live and work. This was not foreseen in the planning of the study, but emerged as the findings were collected and sorted. The places where poor people live suffer combinations of isolation, lack of infrastructure, lack of services, crime, pollution, and vulnerability to disasters like drought, floods and landslips. Stigma of urban place can mean that place of residence must be concealed or dissembled when applying for a job. Inordinate amounts of time may be required for obtaining basics like water. The Chronic Poverty Report 2004-05 devotes a whole chapter (CPRC 2005: 26-35) to "Where do chronically poor people live?" and does a service by describing and analysing spatial poverty traps, their ecological characteristics, poor infrastructure, weak institutions and political isolation. Place, whether rural or urban, as an interlocking dimension of deprivation is so obvious that it is strange that it has not received more prominence. It should be harder to overlook now that it has been named. ${ }^{1 x}$

\section{Poverty of time and energy}


Some of the poorest wish they had work. A very poor woman in a Bangladesh village said:

"These days I have no work," she complains. "If we had land, I would always be busy husking rice, grinding lentils, cooking three times a day. You've seen how hard Jolil's wife works, haven't you? I have nothing to do, so I watch the children and worry. What kind of life is that?"

Hartmann and Boyce 1983: 166-7)

There can be poverty of too much time, and poverty of too little. The evidence from the Voices of the Poor study suggested that unwelcome surplus time was becoming more common for men with unemployment while poverty of both time and energy becoming more common for women. This latter poverty of time and energy was recognised in the South African PPA (May with others 1998: 108-109). It has become more acute for many women as they have become breadwinners in addition to their domestic and reproductive roles (Narayan et al 2000: 111-4). When asked what her dream was, a poor rural woman in Zambia said that it was to be able to go to town, spend time with her friends, and come back again ${ }^{x}$

\section{The body}

The importance of the body, and of health and strength, to poor people shouts out from participatory study after study. The emergent categories from the Voices of the Poor study (Narayan et al 2000) led to a whole chapter entitled The Body. From their analysis of over 250 life-stories of poor people, Parasuraman and his co-authors derive a whole chapter of Listening to People Living in Poverty to "The Labouring Body" (274-297). This, they point out, is often the only resource a person living in poverty is able to use.

"The continuous exertion of their bodies in labour that is underpaid and undervalued leaves them exhausted. Their work is hazardous, seasonal and leaves them vulnerable to outside harm. They are forced to use and sell their bodies as an instrument. They rarely have time to recuperate or rest, and are reduced to what their bodies can do. These processes inscribe on their bodies and leave them to diseases, degenerating illnesses and death"

$$
\text { (ibid:293) }{ }^{\mathbf{x i}}
$$

The central importance of the body to most poor people has been under recognised. The slogan at the head of a poster of the trade union SEWA (the Self-Employed Women's Association) in India reads: OUR BODIES ARE OUR CAPITAL. The body is more important to people living in poverty than it is to professionals. For many, it is their most important asset. But it is at the same time vulnerable, uninsured and indivisible. It has often been weakened by life experiences. It is exceptionally exposed and vulnerable - to hard and dangerous work and accidents, to violence, to sickness, to lack of nutrition, overwork and exhaustion. With an accident or illness it can flip suddenly from being main asset to liability, needing payment for treatment and having to be fed and cared for. It is a recurrent finding that many people fall into bad conditions of deep poverty because of what has happened to their bodies. Yet in general, the priority to poor people of quick, effective and affordable treatment has not been appreciated by professionals. In addition to human and ethical aspects, it may cost much less, and be more feasible, to provide good curative services so that poor people avoid becoming poorer than it is, once they are poorer, to enable them to claw their way back up again.

Negative synergies 
These four neglected dimensions, like others, interact with negative synergies. A poor woman in the Gambia, referring to what could happen during the agricultural season of the rains, said: "Sometimes we are overcome by weeds through sickness or accidents" (Haswell 1975). With seasonal vulnerability of the body, in places which are isolated or cut off, and with seasonal poverty of time and energy when time and energy have high opportunity costs, the disadvantages are compounded, but in ways which are not readily visible to professionals. The power and privileges of others make it worse. It is a cruel twist that poor people are kept waiting in clinics while better dressed middle class people see health staff straight away ${ }^{\mathrm{xiI}}$. Counted as human wellbeing foregone by waiting, the time of the poor people can be worth so much more than that of those who are better off. But this is neither recognised nor acted on. Following any logic of optimising wellbeing, it is the middle classes who should have to wait.

\section{Participation and numbers}

In recent years increasing attention has been paid to combining qualitative and quantitative methods in research (e.g. Booth et al 1998; Marsland et al 2000; Kanbur 2003).

Complementarities have been recognised between the depth and detail contributed by qualitative research and the representativeness and statistical robustness contributed by quantitative research $^{\text {xiii }}$. The benefits of such combinations are not now seriously in dispute. They do, though, tend to overlook the power and potential of participatory approaches and methods, with two assumptions still quite common: first, that participatory approaches only generate qualitative insights; and second, that quantitative data can only be produced by questionnaire surveys or scientific measurement.

To the contrary, many experiences have shown these assumptions to be false. Since the early 1990 s, a quiet tide of innovation has developed a rich range of participatory ways by which local people can themselves produce numbers ${ }^{\text {xiv }}$. The methodological pioneers have rarely recognised the full significance of what they have been doing, written it up for publication, or made it easy for others to learn from them. They have worked in the NE quadrant of figure 5 .

\section{[figure 5 about here]}

The results have been as striking and exciting as they have been unrecognised in professional mainstreams. There are now many examples of numbers being generated by participatory processes and of statistical analysis of these $\mathrm{x}^{\mathrm{xv}}$. The evidence to date indicates that participatory numbers tend to be much more accurate and often more useful than those from questionnaires. Some questionnaires will always be needed, and some, especially time series like the National Sample Survey in India, should surely continue. But for most investigations needing numbers questionnaires may now best be only a last resort.

Participatory analytical activities and applications can generate numbers through counting, measuring, estimating, valuing, ranking, and scoring. Making comparisons is often involved, giving numbers or scores to indicate relative values. Analytical activities are many, for example:

$$
\begin{aligned}
& \text { - } \text { Mapping } \\
& \text { - } \text { Pile sorting } \\
& \text { - } \text { Pie diagramming } \\
& \text { - } \text { Matrix ranking and scoring }
\end{aligned}
$$


- Linkage diagramming

- Pocket voting

- Venn diagramming

Applications of activities like these are many including numerical comparisons of many sorts. Some of the more common derive from

- Resource mapping and modelling (including Participatory GIS)

- Social mapping

- Mobility mapping

- Household listing

- Wellbeing ranking

- Trend and change analysis

- Livelihood analysis

- Seasonal diagramming

- Causal linkage analysis

- The ten seed technique (Jayakaran 2002, 2003)

- Aggregating from focus groups

Many illustrations are now accessible ${ }^{\mathrm{xvi}}$ in the literature. Much of it is grey though some is beginning to be published in journals that are conventionally regarded as of higher status. On the statistical side, the Statistical Services Centre at Reading University ${ }^{x v 11}$ has been in the lead, especially with its remarkable pioneering work with partners in Malawi. To give a taste of some of the range, here are some examples of participatory numbers relating to poverty and to pro-poor programmes:

- Mapping and counting in Nepal. The earliest case of a large-scale survey with participatory visual analysis and no questionnaire may have been in 1992 with ActionAid's use of PRArelated methods, mainly mapping, classifying and counting, in over 130 villages in Nepal (ActionAid-Nepal 1992). This was a survey of utilisation of services. It covered the whole population in the villages and generated 13 tables similar to those from a questionnaire. The population identified by the mapping summed to 35,414 .

- Pile sorting and coping strategies. An SCF (UK) study in 20 Districts in Malawi, Zambia, and Zimbabwe used pile sorting (subdividing piles of 60 stones or seeds) and other participatory methods for a retrospective study on how individual poor farmers coped with the 1992 drought (Eldridge, 1995, 1998). The resulting tables were similar to those from a questionnaire survey.

- The Bangladesh PPA. In 1996 the UNDP PPA in Bangladesh convened focus groups of poor urban and rural women and men and facilitated their analysis of their priorities for "doables", practical measures that would make a difference to their lives. These were aggregated by sex and location to produce cumulative prioritized problem indices which gave them comparative numerical values. These were presented in histograms. Among the findings were, for example, that the top priority for rural women was work, and for urban women water (UNDP $1996: 68)$.

- The Participatory Poverty Index in China. Ways are well known, if not always well practised, for enabling people living in poverty to reflect on and express their priorities. A major problem has been to combine this with comparisons of degrees or deprivation of different communities. Through participatory investigations and iterative pilot testing, a team in China identified eight common indicators as representing people's widespread priorities. Using these, a composite Participatory Poverty Index for each community was constructed 
from poor people's own allocation of personal priorities. This gave numerical expression to relative poverty between communities ( $\mathrm{Li}$ et al 2002; Li and Remenyi and others 2004; Remenyi in draft ${ }^{\mathrm{x} v \mathrm{I}}$. This was, however, lost when the method was taken rapidly to vast scale (pers. comm. Joe Remenyi 2005).

- Violence in Jamaica, Guatemala and Colombia. Focus groups facilitated to undertake participatory studies of urban violence in Jamaica, Guatemala and Colombia identified different types of violence, their seriousness, and the importance, positive or negative, of different related institutions. Their findings were aggregated, including those from Venn diagramming (Moser and Holland 1997; Moser and Mcllwaine 2000, 2001 and 2004). In the Guatemala study this led to a table derived from 176 focus group listings which showed the frequency of mention of 22 different strategies for coping with violence (Moser and Mcllwaine 2001: 140). Contrary to common professional belief, violence categorised as economic was found to be much more widespread than that which was political.

- Voices of the Poor. Aggregation from focus groups was also undertaken in the Voices of the Poor study (Narayan et al 2000) in 23 countries. This involved the views of many hundreds ${ }^{\mathrm{xix}}$ of discussion groups in some 272 communities on, for example, directions of change in violence against women (ibid: 124-131) and characteristics of institutions (ibid: 184 and199-202). The results of these were presented in pie charts and tables.

- The Malawi starter pack study. A participatory study was undertaken in Malawi of the "starter pack" [of seeds, fertiliser etc] programme and of small farmers' ideas of sustainability (Cromwell et al 2001). In each of 30 villages, analysis by 3 focus groups, each bringing together a different category of farmer, included pairwise ranking of the relative importance of 15 indicators of sustainability. The results were combined in a table of mean values across villages by region.

- The Malawi census. When a major debate with pro-poor policy implications arose in Malawi about the size of the rural population as enumerated in the national census, participatory mapping and household listing were undertaken in a carefully selected sample of 54 villages and combined with household visits. Extrapolation indicated a population of 11.5 million compared with the census figure of 8.5 million (Barahona and Levy 2003). The Government census office was not willing to discuss the discrepancy. In their paper, Barahona and Levy elaborate the statistical principles relevant for rigour in such studies.

- The Malawi Targeted Inputs Programme (TIP) study. An ingenious and sensitive sequence of participatory methods, using community mapping with cards, was devised, tested and applied in Malawi to identify what proportions of those who were food secure, food insecure, and extremely food insecure had received inputs from the TIP programme. The programme was intended for the poor. All of the extremely food insecure should have received the inputs, and none of the food secure. The study found that 21 per cent of recipients were food secure, 38.5 percent food insecure, and 40 per cent extremely food insecure, the corresponding figures for non-recipients being 33,40 and 27 percent respectively (Levy 2003).

- Wealth/well-being ranking ${ }^{\mathrm{xx}}$. In wealth or more usually wellbeing ranking, household lists are usually derived from participatory social maps, and written on cards which are then sorted into piles, often by several groups which then meet to triangulate, and then explain the criteria implicit in their allocations. In recent years this has been rapidly adopted as a part of insightful poverty-related research. For the May 2004 Toronto Conference $Q$-Squared in Practice: a conference on experiences combining qualitative and quantitative methods in poverty appraisal, 14 papers were selected from over 60 proposed. In the research reported in these 14, 10 had used PRA-type visuals or tangibles, and no less than 8 had used wealtb/wellbeing ranking. One of the papers (Hargreaves et al 2004a) described a 
breakthrough in South Africa with a household wealth index that made comparisons of poverty possible between people in different communities ${ }^{\mathrm{xxi}}$.

Despite experiences like these, major research organisations like the Operations Evaluation Department of the World Bank are still stuck with old ways of finding out, most notably largescale long questionnaires. Given what we now know, this is inefficient and increasingly unprofessional.

A feature of most of these methods and applications has been time taken to experiment, test and modify them in the field with people in communities, with eclectic borrowing, adaptation and improvisation of methods and sequences in order to assure rigour and a good fit. With the Malawi starter pack study, this was a team activity for an intensive three weeks (pers. comm. Fiona Chambers). In the case of the China PPI it was longer, with iterations. These methods were thus tailor-made and tested for fit. They were not taken off the shelf. Together they give some indication of potential, showing that there can be many alternatives to questionnaires that can lead to better insights and more accurate numbers. ${ }^{\text {xxII }}$ The scope for invention appears unlimited.

Three words of caution are in order. First, the ethical issues of participatory research (as of other research) deserve careful and sensitive attention. Second, the training, behaviour and attitudes of facilitators are critical for good results. This was especially stressed in the South African wealth/wellbeing ranking where training and mentoring of facilitators was intensive and sustained (pers. comm. Anton Simanowitz). Third, given the evidence it is difficult to imagine that approaches like these will not be much more widely adopted, indeed that they are a wave of the future; but experience with other participatory approaches and methods suggests that progress will be slow and accompanied by bad practice. Professional conservatism in bureaucracies, the reproduction of normal professionalism by universities and training institutions, so often the las to learn and change, and inappropriate behaviour and attitudes, can be expected to remain major obstacles.

\section{Listening, learning and immersions}

For learning about poverty in a participatory mode, the behaviours and attitudes of the contextually powerful -the would-be learners, whether senior staff, middle management, field facilitators or researchers - have proved more important than the methods used. They include don'ts such as don't lecture, don't criticise, don't be important, don't dominate, don't rush......and do's such as do be sensitive, respect, sit down, listen, learn, facilitate, take time, be nice to people...

Three streams of activity have contributed much here.

The first is listening and learning. An outstanding example is Harsh Mander's (2001) book Unheard Voices: stories of forgotten lives. These are accounts of the lives and struggles of people in India "who in many ways, have been pushed to the extreme edges of society...street children, sex workers, women, dalit and tribal survivors of atrocities, riot victims, especially women, homeless and destitute people, scavengers of night soil, and those living with leprosy and HIV" (ibid. ix), and people displaced by big development projects, survivors of famines, and human-made and natural disasters. Some are excruciating to read, and tell of realities and resilience which are beyond normal middle class imaginations. Another is Listening to people living in poverty (Parasuraman et al 2003) based on in-depth reading of over 250 life stories of poor people in Vietnam, Pakistan, Nepal, India and Bangladesh. It presents 29 of these, and then derives basic concepts and a framework from them "in an open-ended structure that is 
continuously evolving." (ibid. xiv). This, as might be expected, stresses multidimensionality, (for example "depletion of bodily resources": ibid 202), and power relations between poor people and institutions. Institutions are differentiated into discriminatory, contractual and affirmative, and interactions into constructive, nurturing, redistributive, profitable, maintenance, damaging, punitive, depriving and destructive (ibid 206-214).

The second is what are known as immersions or reality checks (Eyben 2004; Irvine et al 2004 IDS Participation Group, 2005) ${ }^{\mathrm{x}+11}$. These are direct experiences by development professionals who spend a time, usually a few days and nights, living in poor communities with poor people. Pioneered in an organised form as the Exposure and Dialogue Programme by Karl Osner and others in Germany, practices have been spreading and emerging spontaneously in different forms. Senior managers in the World Bank have had their own programme. Perhaps the best known and most influential immersion or reality check was that of Ravi Kanbur, when he was directing the World Development Report 2000/01 in which part of his account was published (World Bank 2000: 2). The trade union SEWA in India has internalised immersions as part of the induction for new staff, who now spend time living and working with their members. Some staff in the INGO ActionAid International practise immersions for their own learning: in the Western Region of Kenya, all 35 staff members now undertake and experience these reality checks twice a year, resulting in "a huge change in the way we think, the way we work" (pers. comm Ashish Shah August 2005).

The third has not to my knowledge been repeated but just might be a wave of the future. It is another form of immersion that had remarkable results. In 2002 SDC (the Swiss agency for Development and Cooperation) organised a four-week participatory and qualitative study of 26 poor households, with careful and sensitive training and facilitation. SDC staff spent entire days, from waking to sleeping, and without taking notes - to avoid distraction and so that their hands could be free, living and working with the families. There were striking insights such as how much more important shelter and the quality of housing were to poor people than had been supposed (Jupp et al 2003). For the researchers, the experience proved personally and professionally transformational. They reflected, for example "We had no idea what poverty was really like until we were involved in this study" and "I thought I knew about village life as my roots are in the village and I still visit family in my village from time to time. But I know nothing about what it is like to be poor and how hidden this kind of poverty can be" (Jupp 2004: 4 and pers comm). As the trainer and facilitator observed, despite the risks, the outcomes of the exercise were extraordinary.

\section{Participation, Creativity and Pluralism: a pro-poor paradigm?}

A difficulty in writing this paper has been a sense of an explosion of poverty-related participatory activities in recent years. Perhaps we development professionals, especially negative academics, have been so aware of bad practice in the name of participation that we have overlooked the trend of improving and at times brilliant innovative practice ${ }^{\mathrm{xxiv}}$. It is scattered, and often unconnected, and quite often short-lived. Much of it is by NGO staff and dispersed and isolated in small organisations and countries of the South. Much of it turns standard labelling and branding, central ownership and control, and the ego associated with these, on their heads ${ }^{\mathbf{x x v}}$. There is a telling example in the history of Reflect. In its early days, after piloting, Reflect had a Mother Manual. But this was quickly abandoned. The idea of a centralised, standardised, detailed right way of doing things was a paradigmatic misfit. It is the principles, not the details of practice, or even the label, that matter. Reflect in Nepal now has 16 different local names, each taking its own form with local ownership and fit (pers. comm. Bimal Phnuyal). Similar isolated creativity and diversity are found with the work of consultants who innovate in a participatory mode. 
Unfortunately, the one-off nature of most consultancy means that they lack time, sponsorship or even inclination to reflect on, record, share or spread what they have evolved; and those who commissioned their work rarely provide for such activities. Instead they tick the box of satisfactory completion, and move on to other things. Much promising participatory innovation is, thus, isolated or still-born.

Using the word paradigm to mean concepts, ideas, perceptions, values, methods, behaviours and relationships which are mutually supporting and reinforcing, we can identify here an emergent paradigm of participation and pluralism, and with it of perceptions of poverty. Participation goes with changing power relations and behaviours, and sharing; pluralism goes with openness, mutual learning, eclectic improvisation and creativity; and a plurality of perceptions of poverty are those both of professionals and of people living in poverty. In this paradigm, it is the experience, conditions and realities of poor people, and their analysis and expression of these, that come first. For this to happen well, professional unlearning has its part to play. As with PPAs, with sensitive and hidden topics, with nets or webs of disadvantage, with participatory numbers, and with listening, learning and immersions, the primary role of professionals is to convene, facilitate, learn and then later communicate. This is not to undervalue trained professional competences. It is not to substitute one fundamentalism for another. It is, rather, to correct an imbalance. It is to start in another place, upending the normal, and empowering those who lack power through enabling them to conduct their own analysis and supporting them. It is then that the diversity of deprivations becomes more evident, and the many forms that multidimensional poverty can take. It is then, too, that we may conclude that there is no one final best set of concepts, ideas, perceptions, methods or behaviours, but only continuous mixing, adoption, adaptation, improving, improvising and creativity, energised by commitment and informed by search, practice, doubt, and reflection. Participation and poverty both take many forms. And the potentials for combining them to enhance the wellbeing of those who suffer multiple deprivations have scarcely begun to be tapped. Poverty may never be made history. But we can ask whether a precondition for its sharp reduction is that powerful professionals become more participatory and get closer to and learn more from those who live their lives in poverty; and then act on what they experience, learn and feel.

8 March 2006

Robert Chambers

r.chambers@ids.ac.uk

References: italics $=$ not referred to in the text

ActionAid-Nepal 1992 Participatory Rural Appraisal Utilisation Survey Report Part 1: Rural Development Area Sindhupalchowk, Monitoring and Evaluation Unit, ActionAid-Nepal, P.O.Box 3192, Kathmandu.

Archer, David forthcoming "Seeds of success are seeds for potential failure: learning from the evolution of Reflect" in Brock and Pettit eds title pending

Archer, David and Kate Newman compilers 2003 Communication and Power: Reflect practical resource materials. ActionAid, London N19 5PG www.reflect-action.org

Archer, David and Nandago Maria Goreth 2004 "Participation, literacy and empowerment: the continuing evolution of Reflect" Participatory Learning and Action 50: 35-44 
Barahona, Carlos and Sarah Levy 2003 How to generate statistics and Influence Policy Using Participatory Methods in Research: Reflections from Malawi 1999-2002. Working Paper 212, IDS Sussex, November

Beck, Tony 1994 The Experience of Poverty: Fighting for respect and resources in village India, Intermediate Technology Publications, London

Booth, D., J. Holland, J. Hentschel, P.Lanjouw, and A. Herbert 1998 Participation and Combined Methods in African Poverty Assessment: renewing the agenda. Report commissioned by DFID for the Working Group on Social Policy, Special Program of Assistance for Africa.

Brock, Karen and Rosemary McGee eds 2002 Knowing Poverty: Critical reflections on participatory research and policy. Earthscan, London and Sterling VA

Brock, Karen and Jethro Pettit eds forthcoming title pending

Chambers, Robert 1997 Whose Reality Counts? Putting the First Last. ITDG Publications, Rugby, UK

Chambers, Robert 2002 "Power, knowledge and policy influence: Reflections on an experience" in Brock and McGee eds Knowing Poverty : 135-165

Chambers, Robert 2003a "Qualitative approaches: self-criticism and what can be gained from quantitative approaches" in Kanbur ed Q-Squared: 22-27

Chambers, Robert 2003b “The Best of Both Worlds", in Kanbur ed Q-Squared: 35-45

Chambers Robert, 2005 Ideas for Development. Earthscan, London and Sterling VA

Cooke, Bill and Uma Kothari eds 2001 Participation: the New Tyranny?. ZED Books, London, New York

Cornwall, Andrea and Alice Welbourn eds 2002 Realizing Rights: Transforming Approaches to Sexual and Reproductive Well-being. ZED Books, London

CPRC 2005 The Chronic Poverty Report 2004-05. Chronic Poverty Research Centre, Institute for Development Policy and Management, University of:Manchester, Manchester UK

Cromwell, E., P.Kambewa, R. Mwanza, and R.Chirwa with KWERA Development Centre 2001 Impact Assessment Using Participatory Approaches: 'Starter Pack' and Sustainable Agriculture in Malawi, Network Paper No 112, Agricultural Research and Extension Network, Overseas Development Institute, London

Education Action 1994 - 2006 continuing twice a year in four languages ActionAid, London www.reflect-action.org

Eldridge, Christopher 1995 Methodological notes, instructions to facilitators, household responses to drought study in Malawi, Zambia, and Zimbabwe, Save the Children, UK 
Eldridge, Christopher 1998 Summary of the Main Findings of a PRA Study on the 1992 Drought in Zimbabwe, Save the Children, UK

Eldridge, Christopher 2001 Investigating Change and Relationships in the Livelihoods of the Poor Using an Adaptation of Proportional Piling, Save the Children, UK.

Estrella, M. with J. Blauert, D. Campilan, J. Gaventa, J. Gonsalves, I.Guijt, D. Johnson, and R. Ricafort eds 2000 Learning from Change: issues and experiences in participatory monitoring and evaluation. Intermediate Technology Publications, London

Eyben, Rosalind 2004 Immersions for Policy and Personal Change. IDS Policy Briefing Issue 22, IDS Sussex, UK July

Francke, M 2003 "Including the poor excluded people of Ayacucho in the construction of the "truth": Reflections on methods and processes for the realisation of rights", unpublished paper available from mfrancke@pucp.edu.pe

Guijt, Irene 2000 'Methodological issues in participatory monitoring and evaluation'. In Estrella with others eds Learning from Change pp 201-216.

Hargreaves, James R, Linda Morison, John S.S Gear, John D.H.Porter, Mzamani B Makhubele, Julia C. Kim, Joanna Buzsa, Charlotte Watts, and Paul M Pronyk 2004a "Hearing the voices of the poor": Assigning poverty lines on the basis of local perceptions of poverty: a quantitative analysis of qualitative data from participatory wealth ranking in rural South Africa", paper presented to Q-Squared in Practice: a conference on experiences combining qualitative and quantitative methods in poverty appraisal, Toronto 15-16 May 2004

Hargreaves, James R, Linda Morison, John S.S Gear, John D.H.Porter, Mzamani B Makhubele, Julia C. Kim, Charlotte Watts, and Paul M Pronyk 2004b The assessment of household wealth in health studies in developing countries; a comparison of participatory wealth ranking and survey techniques from South Africa, typescript [correspondence to James Hargreaves, Clinical Research Unit, London School of Hygiene and Tropical medicine, Keppel St, London WC1E 7HT email jimharg@soft.co.za ]

Hartmann, Betsy and James Boyce 1983 A Quiet Violence: View from a Bangladesh Village. Zed Press, London

Haswell, Margaret 1975 The Nature of Poverty: a case history of the first quarter-century after World War II, Macmillan, London and Basingstoke

Hickey, Samuel and Giles Mohan eds 2004 Participation: from turanny to transformation? ZED Books, London and New York

Holland, Jeremy with James Blackburn eds 1998 Whose Voice? Participatory research and policy change. IT Publications, London

IDS Participation Group 2005 Immersions and Reality Checks, source materials, available from Jane Stevens, Participation Group, Institute of Development Studies, Sussex BN1 9RE, UK i.stevens@ids.ac.uk 
International HIV/AIDS Alliance 2003 Developing HIV/AIDS Work with Drug Users: a guide to participatory assessment and response. International HIV/AIDS Alliance, Brighton UK

Irvine, Renwick, Robert Chambers and Rosalind Eyben 2004 Learning from poor people's experience: immersions, Lessons for Change in Policy and Organisations No 13, IDS Sussex, UK

Jayakaran, Ravi .2002 The Ten Seed Technique. World Vision, China. ravi iayakaran@,wvi.org

Jayakaran, Ravi 2003 Participatory Poverty Alleviation and Development, a comprehensive manual for development professionals. World Vision, China. ravi_jayakaran@wvi.org

Joseph, Sam 2005 Rwanda Ubudehe: Local Collective Action. update June 2005, Kigali, Rwanda

Jupp, Dee 2003 Views of the Poor: the perspective of rural and urban poor in Tanzania a recounted through their stories and pictures. Swiss Agency for Development and Cooperation, Berne, May

Jupp, Dee 2004 "Views of the Poor: Some thoughts on how to involve your own staff to conduct guick, low cost but insightful research into poor people's perspectives" available on request from diupp@tiscali.co.uk

Kanbur, Ravi 2000 "Basrabai's story" in World Bank 2000 Attacking Poverty: 2

Kanbur, R. ed. 2003 Q- Squared: qualitative and quantitative methods of poverty appraisal. Permanent Black, D-28 Oxford Apartments, 11, 1.P. Extension, Delhi 110092

Kar, Kamal 2003 Subsidy or Self-respect? Participatory Total Community Sanitation in Bangladesh. Working Paper 184, IDS Sussex UK

Kar, Kamal and Kath Pasteur 2005 bbbbbb

Levy, Sarah 2003 "Are we targeting the poor? Lessons from Malawi", PLA Notes 47: 19-24

Li, Xiaoyun et al 2002 Preparing a Methodology for Development Planning in Poverty Alleviation under the New Poverty Strategy of PRC, ADB/TA3610-PRC, Asian Development Bank, Manila

Li, Xiaoyun and Joe Remenyi, LiZhou, Wang Sibin, Zhang Chuntai,Liu Yonggong 2004 Who's Poverty? Making Poverty Mapping and Monitoring Participatory, typescript, College of Humanities and Development, China Agricultural University

MacGillivray, A., C. Weston, and C. Unsworth 1998 Communities Count! a step by step guide to community sustainabilitv indicators. New Economics Foundation, London

Mander, Harsh 2001 Unheard Voices: stories of forgotten lives. Penguin Books, New Delhi, London, New York, Victoria, Toronto, Auckland 
Marsland, N., I.M.Wilson, S. Abeyasekera and U.K. Kleih 2000 A methodological framework for combining quantitative and qualitative survey methods. Statistical Guide. Statistical Services Centre, University of Reading, Reading UK. www.reading.ac.uk/ssc

May, Julian, with Heidi Attwood, Peter Ewang, Francie Lund, Andy Norton and Wilfred Wentzal 1998 Experience and Perceptions of Poverty in South Africa, Final Report of the South African PPA, Praxis Publishing, Durban

Mayoux, Linda and Robert Chambers 2005 "Reversing the Paradigm: Quantification, participatory methods and pro-poor impact assessment", Journal of International Development. 17, 271-298

McGee, Rosemary, with Josh Levene and Alexandra Hughes 2002 Assessing Participation in Poverty Reduction Strategy Papers: a desk-based synthesis of experience in Sub-Saharan Africa, IDS Research Report 52, IDS Sussex, February

Mda, Z 1983 When People Play People: Development Communication through Theatre, Zed Books, London

Moser, C. and J. Holland 1997 Urban Poverty and Violence in Jamaica. World Bank Latin American and Caribbean Studies Viewpoints. Washington DC: World Bank.

Moser, C.and C. Mcllwaine. 2000 Urban Poor Perceptions of Violence and Exclusion in Colombia. Latin American and Caribbean Region, Environmentally and Socially Sustainable Development Sector Management Unit. Washington DC: World Bank.

Moser, C. and C. Mcllwaine 2001 Violence in a Post-Conflict World: Urban Poor Perceptions from Guatemala, Latin America and Caribbean Region, Environmentally and Socially Sustainable Development Sector Management Unit. Washington DC: World Bank.

Moser, Caroline and Cathy Mcllwaine 2004 Encounters with Violence in Latin America: Urban poor perceptions from Colombia and Guatemala. Routledge, New York and London

Mukherjee, Neela. 1995 Participatory Rural Appraisal and Questionnaire Survey: Comparative Field Experience and Methodological Innovations. Concept Publishing Company, A/1516, Commercial Block, Mohan Garden, New Delhi 110059.

Mukherjee, Neela 2001 Participatory Learning and Action - with 100 field methods, Concept Publishing Company, A/15-16, Commercial Block, Mohan Garden New Delhi 110059.

Narayan, Deepa, Robert Chambers, Meera K. Shah and Patti Petesch 2000 Voices of the Poor: Crying Out for Change. Oxford University Press for the World Bank

Parasuraman, S., Gomathy, Kumaran Raj and Bina Fernandez 2003 Listening to people living in poverty. Books for Change, 139 Richmond Road, Bangalore 560025 www.booksforchange.net

PLA Notes (formerly RRA Notes, and now Participatory Learning and Action), triannual, International Institute for Environment and Development, 3 Endsleigh Street, London WC1H ODD. Email sustag@iied.org Website www.iied.org 
PRA Report Video c 1993 Video by World Vision, Australia, of a PRA Training in Zambia

PRAXIS 2001 The Politics of Poverty: a tale of the living dead in Bolangir. Books for Change Bangalore

Reason, Peter and Hilary Bradbury eds 2001 Handbook of Action Research: Participative Inquiry and Practice. Sage Publications, London, Thousand Oaks, New Delhi

Remenyi, Joe forthcoming Poverty Analysis, Poverty Mapping and Participation in China in Brock and Pettit eds book

Robb, Caroline 2002 Can the Poor Influence Policy? Participatory Poverty Assessments in the Developing World. The World Bank and International Monetary Fund, Washington DC

RRA Notes 15 (1992) Special Issue on Applications of Wealth Ranking, International Institute for Environment and Development, London

Scarry, E. 1985 The Body in Pain, the Making and Unmaking of the World. Oxford University Press, New York [cited in Parasuraman et al]

Sen, Amartya 1999 Development as Freedom. Oxford University Press

Shah, M. Kaul (1999) 'A Step-by step guide to popular PLA tools and techniques'. Chapter 2 in Shah et al eds Embracing Participation in Development

Shah, M. Kaul S. Degnan Kambou and B.Monahan, B. eds 1999 Embracing Participation in Development: worldwide experience from CARE's reproductive health programs, USA CARE, 151 Ellis Street, Atlanta, Georgia 30303.

Simanowitz, A and B. Nkuna 1998 Participatory Wealth Ranking Operational Manual, Small Enterprise Foundation, Tzaneen, South Africa [contact a.simanowitz@ids.ac.uk]

Simanowitz, A., B. Nkuna and S. Kasim 2000 Overcoming the obstacles to identifying the poorest families, unpublished report [contact a.simanowitz@,ids.ac.uk]

UNDP, Bangladesh 1996 UNDP's 1996 Report on Human Development in Bangladesh. Volume 3 Poor people's perspectives, UNDP, Dhaka

Walker, Sarah and Imran Matin 2006 "Changes in the lives of the ultra poor: an exploratory study", Development in Practice 16 (4): 80-84

Welbourn, Alice 1995 Stepping Stones: a training package on gender, HIV, communication and relationship skills. Manual and video, Strategies for Hope, ActionAid, London

Welbourn, Alice 2002 "Gender, sex and HIV: how to address issues that no one wants to hear about", in Cornwall and Welbourn eds Realizing Rights pp 99-112

White, Sarah and Jethro Pettit 2004 "Participatory methods and the measurement of well-being" Participatory Learning and Action 50: 88-96 
White, Sarah and Jethro Pettit forthcoming "Participatory methods and the measurement of wellbeing", chapter in a book edited by Mark McGillivray on the measurement of well-being

World Bank 2000 Attacking Poverty. World Development Report 2000/01. Oxford University Press for the World Bank

$$
\text { [ends] }
$$

' I recognise that many usages are possible. In another context I used deprivation to encompass more than poverty. Poverty was "a condition of lack of physical necessities, assets and income. It includes, but is more than, income-poverty. Poverty can be distinguished from other dimensions of deprivation".

Deprivation was "lacking what is needed for well-being. Deprivation has dimensions which are physical, social, economic, political and psychological/spiritual. It includes forms of disadvantage such as social inferiority, physical weakness, isolation, poverty, vulnerability, powerlessness and humiliation" (Chambers 1997: xiv, xv).

${ }^{11}$ For PPAs see Holland with Blackburn 1998 for accounts and analysis of Ghana, Zambia, South Africa and Mozambique; and Norton 2001 and Robb 2002 for authoritative reviews.

"' For example, a group of seven school girls in M'tendere Comp;ound, Lusaka, matrix scored a typology of sex partners and preferences, with 16 categories of male partners scored against 5 criteria (Shah 1999:52) ${ }^{\mathrm{v}}$ For the Internal Learning System see chapters by Nagasundari, Narendranath and Noponen in Brock and Pettit eds forthcoming

${ }^{v}$ For a self-critical review of the process see Chambers 2002

${ }^{\mathrm{V}}$ For a more extended analysis of the origins and process of developing these diagrams, see Chambers 2002: $147-8$

vil The web of disadvantages has been expanded and filled out from the same categories for sexuality by

Susan Jolly ( s.jolly@ids.ac.uk ), and for transgender and for HIV/AIDS by Giuseppe Campuzano

vin For more on the multiple adverse interactions of tropical seasonality for poor people see Robert

Chambers, Richard Longhurst and Arnold Pacey eds 1981 Seasonal Dimensions to Rural Poverty. Frances

Pinter, London (out of print). For an update in 1993 see Chapter 4 in my book Challenging the Professions. Intermediate Technology Publications, which also has a short bibliography. This remains a lamentably neglected subject despite its profound policy implications for pro-poor policy and practice.

${ }^{\mathrm{ix}}$ This is not to suggest at all that this is a new insight. For the UK, for example, see Friedrich Engels The Conditions of the Working Class in England (1845) and Charles Dickens Hard Times (1854). The question is whether the multiple interactions of disadvantage which have spatial dimensions have been adequately appreciated by professionals.

$\times$ The source is a video of a PRA training in Zambia in 1993, entitled The PRA Report. made by World Vision, Australia

${ }^{x 1}$ The authors refer at the end of this paragraph to Scarry 1985 , but these conclusions flow too from their own analysis.

xin This was a repeated complaint in focus groups in the Voices of the Poor study (Narayan et al 2000:

chapter 5)

xi1 For an attempt to summarise the benefits of quantification see Chambers 2003a

${ }^{x i v}$ For an early comparison with questionnaire approaches see Mukherjee 1995.

${ }^{x v}$ For an overview and sources in mid 2003, see Robert Chambers "Participation and Numbers", PLA

Notes 47, August 2003: 6-12, itself a revision and update of Chambers 2003a "The Best of Both Worlds" in Kanbur ed Q-Squared. 2003: 35-45. See also Mayoux and Chambers 2005. These articles present more evidence and reference more sources that this current paper which, however, includes some new material. ${ }^{\mathrm{xv} 1} \mathrm{~A}$ rich source is the journal PLA Notes now Participatory Learning and Action. Other sources include the websites of the Statistical Services Centre at Reading University www.reading.ac.uk/ssc and of the Participation Group at the University of Sussex www.ids.ac.uk/ids/particip See also Mukherjee 2001. xvi1 Work of the Statistical Services Centre at Reading University can be found at www.reading.ac.uk/ssc check

xvil The method is described in the sources. It would take too much space to describe it here 
${ }^{\mathrm{xix}}$ A precise figure cannot be given for two reasons: the total number of discussion groups was not recorded for every country though it was probably over 1,500 (Narayan et al 2000: 298-305); and not all discussion groups produced relevant comparable data suitable for analysis.

${ }^{\mathrm{xx}}$ For an early treatment of wealth/wellbeing ranking see $\underline{\text { RRA Notes }} 15$ Special Issue on Applications of Wealth Ranking, IIED, London, 1992

${ }^{x x i}$ See also Hargreaves et al 2004b. The Hargreaves et al sources also refer to Simanowitz and Nkuna 1998 and 2000

xxiI My assertion of accuracy would need a further paper. I would be delighted to discuss this with anyone who is interested. Earlier evidence was in my book Whose Reality Counts? chapters 6 and 7

${ }^{\mathrm{x} x i 1}$ For an outline of the history of immersions, see Eyben et al 2004. Immersions are promoted and provided by the Association for the Promotion of North-South Dialogue (www.exposure-

nsd.de/engl.html) and on an increasing scale by ActionAid International (contact

Sonya.ruparel@actionaid.org )

${ }_{\text {xxiv }}$ For example the Cooke and Kothari eds book Participation: the New Tyranny? (2001) focused on bad practices and drew attention away from evolving good practice and potentials, now however more recognised in its successor Hickey and Mohan eds Participation: from Tyranny to Transformation? (2004).

${ }^{\mathrm{xxv}}$ For an insightful reflection on ego and branding in the case of Reflect, see Archer forthcoming. 


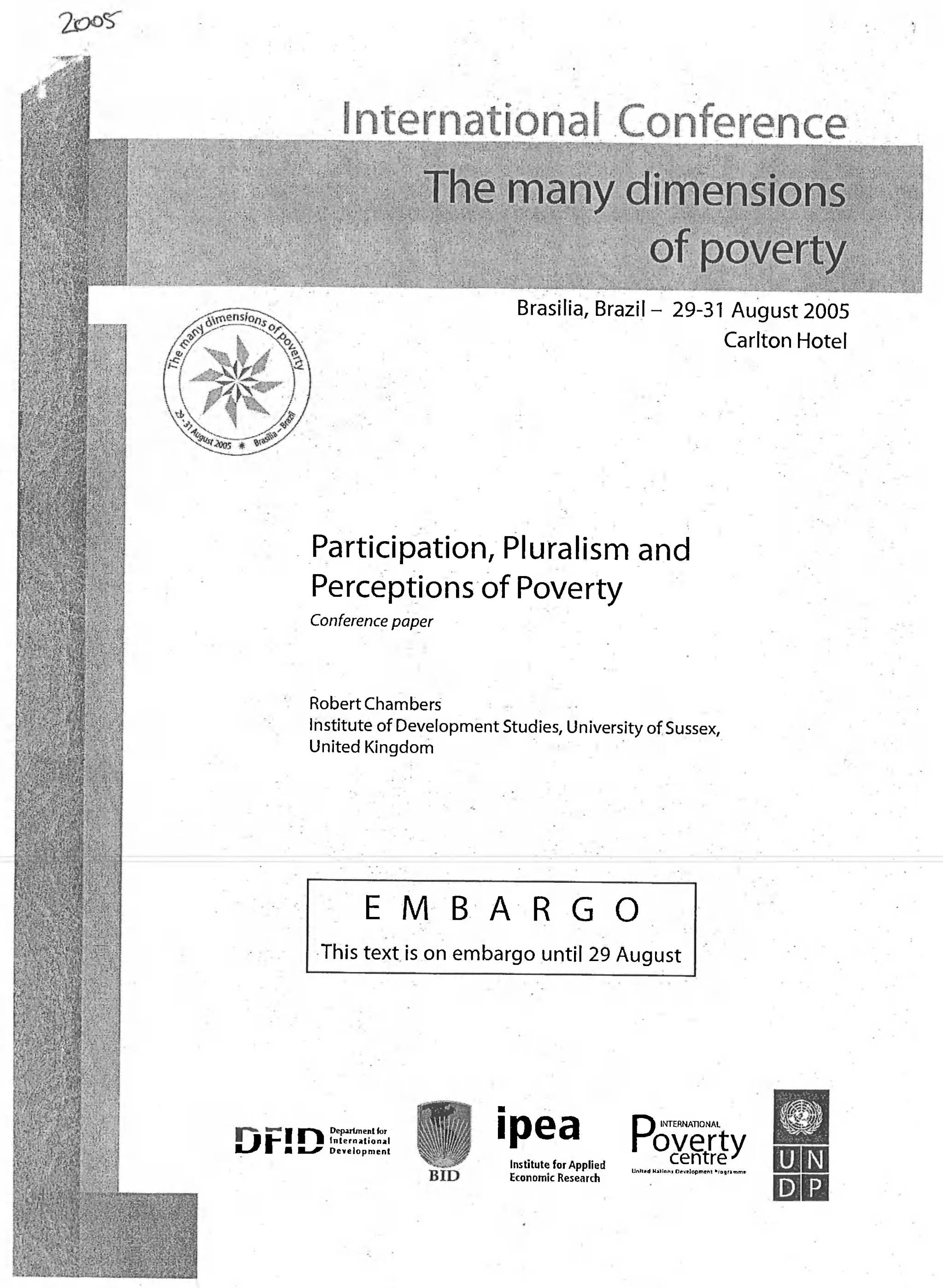


Paper for the International Conference on Multidimensional Poverty: Brasilia August 29-31 2005

Participation, Pluralism and Perceptions of Poverty

Robert Chambers Institute of Development Studies University of Sussex The United Kingdom

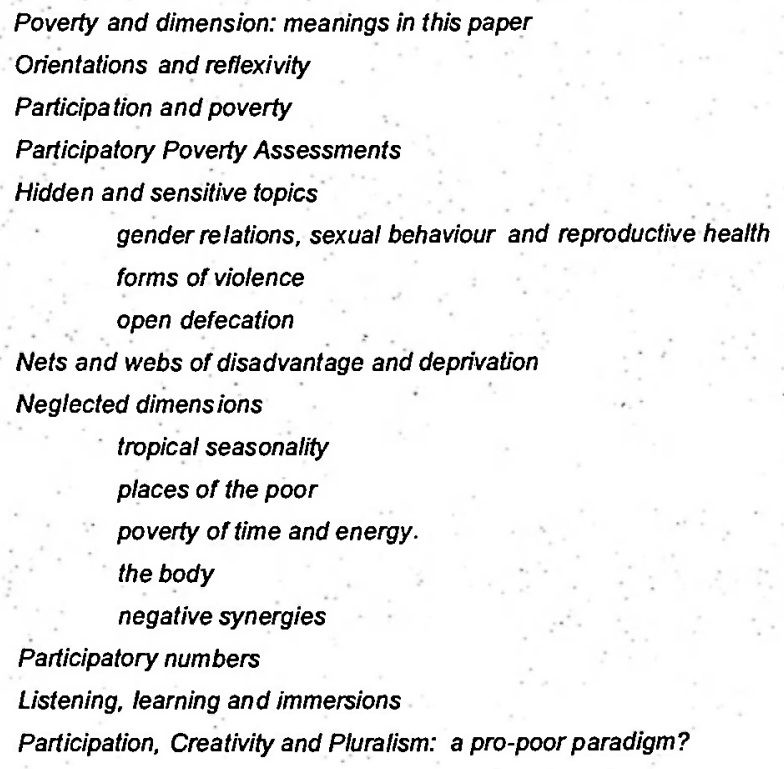

Since I may be the only person presenting in this conference on participatory approaches and methods, I have attempted an overview of participatory practices, evidence and associated ideas and insights about poverty. I recognise that the paper is both too long and the coverage woefully inadequate. But I hope the sources cited will encourage readers and make it easier for them to check what I am saying and to follow up if they wish and as I hope they will. 
Poverty and dimension: meanings in this paper

In any paper, meanings of words are both problems and opportunities. One common problem is when an author uses the same word in more than one sense. Another, perhaps even more common, is when readers attribute meanings to words which are different from those intended by the author. On the flip side, there is the opportunity for an author to be consistent in usage and meanings: this I shall attempt but surely fail to do. Another opportunity is to say at the outset what words are going to be used to mean. This I shall now try to do with the two words which are central in this conference: poverty, and dimension. I am not in the least saying that this is what they ought to mean, or what others should mean by them, only that these are the meanings intended here.

Poverty. In this paper, I take poverty to mean bad condition or experience of life This is more than material poverty or lack. It is the meaning implied by the statement with which the World Development Report (WDR) 2000/01 Attacking Poverty opens "Poverty is pronounced deprivation in wellbeing" (World Bank 2000: 15). "Multidimensional poverty" is then the same as "multidimensional deprivation".' Well-being I take to be the experience of good quality of life, and ill-being, its opposite, the experience of bad quality of life.

It can be objected that with this definition, a fat cat with money pouring out of his (most are men) ears but whose mind is a waking nightmare and whose relations with his wife are horrible could be said to be poor or suffering from poverty. Yet in commonsense terms we would never describe him as poor. This is, however, not a serious problem when we take account of the nets or webs of deprivation, powerlessness and disadvantage (see Nets and Webs of Deprivation and Disadvantage below). The fat cat does not suffer significantly from the interactions of these. So the definition of poverty can be qualified so that it applies to bad conditions and experiences of life in which material and other 
deprivations and disadvantages interact and reinforce each other as they do in the nets and webs.

Dimension. In the literature this is used in at least three senses.

First, the Research Group on Wellbeing in Developing Countries at the University of Bath (White and Pettit in press) describes three dimensions of wellbeing, and by implication of its opposites, illbeing, poverty or deprivation. These are subjective, objective, and interactive or process. Subjective can be taken to mean what is experienced, objective to refer to conditions or causes outside a person, and interactive or process to encompass how subjective (internal and experiential) and objective (external) affect each other.

A second sense of dimension is that in the WDR 2000/2001 (see e.g. v, 1, 15 and passim) which "sets out actions to create a world free of poverty in all its dimensions". The multiple deprivations listed in the Report, besides low income or consumption, include lack of education, health, food and shelter, fear powerlessness and voicelessness. And the WDR says that there is "a powerful case for bringing vulnerability and its management to center stage" (ibid 32). The WDR implicitly separates some of the more experiential dimensions of poverty from their determinants (e.g. ibid:34).

A third and broader usage includes the first two and extends dimension to include causes to a greater extent. Thus, for example, "Corrupt and arbitrary governance constitutes a significant factor that defines and contributes to the various other dimensions of poverty" (Parasuraman et al 2003: 33). This was also the sense which evolved out of the Voices of the Poor process, in which participatory approaches and methods were used to enable poor people in close to 300 communities in 23 countries to express and analyse their realities (Narayan et al 2000). After stating that "The dimensions of deprivation are 
multiple", ten "Dimensions of Powerlessness and llibeing" were elicited and described:

\begin{tabular}{|c|c|}
\hline Capabilities: & lack of information, education, skills, confidence \\
\hline Livelihoods and assets & precarious, seasonal, inadequate \\
\hline Places: & isolated, risky, unserviced, stigmatised \\
\hline The body: & hungry, exhausted, sick, poor appearance \\
\hline Gender relations: & troubled and unequal \\
\hline Social relations: & discriminating and isolating \\
\hline Security: & lack of protection and peace of mind \\
\hline Behaviours: & disregard and abuse by the more powerful \\
\hline Institutions: & disempowering and excluding \\
\hline
\end{tabular}

(Narayan et al 2000: 248-9 and figure 2

below)

Many dimensions can be identified, as above. They may be physical, material, social and/or psychological, and can be experiential (subjective?), external to a person (objective?), related to interaction or process, or a cause, or often some combination of these. There seems no gain from restricting the meaning of dimension. In this paper I shall use it in these various and several senses, relying on other words and the context to indicate particular meaning.

In a spirit of pluralism I recognise and celebrate the fact that there will be other meanings and other categories, not least those of Sen (e.g.1999), represented, expressed and used, in this conference. I am not asserting any sort of primacy to those I struggle with in this paper, only trying to be consistent in their use.

Orientations and Reflexivity 
It gives a useful perspective to recognise how far we have come. A well-balanced view of professional views of poverty is beyond my competence. What stands out, though, is how the reductionist money-metric view of poverty has been, and to some extent remains, disproportionately dominant is much development discourse. For some economists and others it is sort of a bedrock; for others, a sort of default mode. Reviewing the important debates on poverty and the poverty line in India Tony Beck observed (1993: 16) that "..the central preoccupation of the majority of authors on poverty has been the accuracy of the statistics and the statistical techniques used". A tempting caricature of the concept of poverty implied by such debates could be of a top-down, centreoutwards, ivory tower, mathematical construct, overfed and driven by questionnaires, statistics, computers, regressions, equations, graphs and tables. In this view, it could be seen as sustained by erudite, incestuous and selfreproducing systems of high status organisations and departments, and by teaching, textbooks, international conferences, prestigious journals and rigorous professional peer review. Economists, it might be suggested, construct their own reality of poverty based on reported income or consumption, provoking the verse:

$$
\begin{aligned}
& \text { Economists have come to feel } \\
& \text { What can't be measured isn't real } \\
& \text { The truth is always an amount } \\
& \text { Count numbers, only numbers count }
\end{aligned}
$$

But those, like myself, who enjoy writing this sort of stuff about economists, have to look at ourselves. We too find it useful and indeed necessary to refer to poverty lines; and their accuracy and what they represent do matter. We too have our biases and predispositions. Arguably, any writing on development should be preceded by a reflexive paragraph outlining those of which the author is aware. Let me list some of mine. As a lapsed biologist and historian, and now undisciplined social scientist, I take pleasure, and have sustained a livelihood, by looking for gaps between professions and aspects of realities that seem to have 
been overlooked or understudied. I recognise that I am liable to exaggerate the importance of such gaps, and am vulnerable to glee when I believe I have discovered a misperception of "normal" professionalism and professionals. In my view, numbers and statistics are important, but often more flawed than their users recognise. I tend to privilege the knowledge, values and abilities of poor and excluded people over those of established groups, especially academics and powerful old men. I have been repeatedly astonished at the insights and capabilities that have been revealed by participatory behaviours, attitudes, approaches and methods. So about these predispositions and biases at least (and there are surely others) readers have now been alerted and warned.

\section{Participation and Poverty}

In the past decade and a half we have come a long way in the invention, evolution and spread of participatory approaches and methods and their contributions to understanding poverty. A new pluralism of methodology and perception has opened up. A thousand flowers have bloomed. At the same time, especially when spread by big bureaucracies, many have turned into weeds. In parallel, though, there have been innumerable examples of good practice. Sourcebooks, guides and manuals have proliferated, and have then increasingly been superseded by eclectic creativity. Those participatory methodologies which have become best known and most widespread include: Participatory Action Research, PRA (originally participatory rural appraisal, now often participatory reflection and action) and PLA (participatory learning and action), Participatory Technology Development, Appreciative Inquiry, Planning for Real, Popular Education, Popular Theatre, Reflect and various forms of Participatory Monitoring and Evaluation (PM and E)". Well facilitated, in various forms and combinations, these to varying degrees can enable and empower poor and marginalised people to conduct and learn from their own analyses, express 
their values and priorities, and plan, act, monitor and evaluate for themselves. They have also provided many insights into dimensions of poverty.

Five clusters of related innovation and insight stand out:

Participatory Poverty Assessments

Hidden and sensitive topics

Nets and webs of disadvantage and deprivation

Participatory numbers

Listening, learning and immersions

There is no way these can be adequately covered in a paper of this length. Instead, I shall attempt to summarise them and give references to what seem to me to some key sources.

Participatory Poverty Assessments

Participatory Poverty Assessments (PPAs) evolved in the early 1990s, notably in Ghana (1993-4), Zambia (1993- ) and South Africa (1995- ) and have since become widespread, with probably hundreds now complete counting those at subnational as well as national levels. By 2002 more than 60 countries had undertaken PPAs with assistance from the World Bank, with a similar number supported by other agencies (Robb 2002: 3). Increasingly PPA-type studies have been carried out at subnational levels, for example in Bolangir District in Orissa, India (PRAXIS 2001).

A PPA was described in The Rough Guide to PPAs (Norton et al 2001: 6) as "an instrument for including poor people's views in the analysis of poverty and the formulation of strategies to reduce it through public policy". In many of these focus groups were combined with PRA methods of analysis. Groups have been facilitated to create and analyse their realities often using visuals and tangibles for methods such as participatory mapping, preference ranking, matrix scoring, 
Venn diagramming, wealth or wellbeing ranking, and many others. They have covered many aspects of life and experience such as poor people's priorities, access and institutions, gender relations, causal linkages, seasonal variations, and trends and changes

Repeatedly, PPAs have opened up aspects of poverty which had been relatively overlooked or given inadequate priority. Reviews of PPAs (Booth et al 1998: 5-7) found that they highlighted:

- A sense of isolation, from services, markets, government institutions and information, with physical isolation a key factor

- The key importance of water supplies

- Security of life and livelihood as a primary concern

- Access to curative health as a consistently high priority

- Local visions of poverty relating to prevailing community norms

- Differential vulnerability according to inherent or socially constructed characteristics of individuals (gender, age, childlessness, health status, disability and individual pathologies such as drunkenness)

- Hunger and dietary inadequacy as a distinct dimension of deprivation

- The seasonality of access and vulnerability

- Intra-household poverty dynamics

- The decline of traditional, and insufficiency of alternative, safety nets

- Community-level poverty versus household or individual poverty

Caroline Robb concluded her review of PPAs (second edition, 2002: 104-5)

"The moral imperative for giving the poor a voice in the poverty debate is self-evident. The bonus is that engaging with the poor also leads to better technical diagnosis of problems and implementation of solutions. Through PPAs, the poor deepen our understanding of poverty and can influence policymaking. This new approach challenges traditional power 
relations... when undertaken in an environment of increased trust, PPAs can present opportunities for a more open dialogue and greater understanding between the powerless and those in power."

The processes for Poverty Reduction Strategy Papers (PRSPS) which have superseded PPAs in prominence have been criticised for inadequate consultation. Some, however, have drawn on PPAs, a clear example being Uganda where "the PPA predated the PRSP concept, but was used extensively in revising the national strategy, which became the PRSP" (McGee et al 2002: 8) In a remarkable evolution in Rwanda, a PPA process, ubudehe, has been developed and spread in which each commune conducts its own PPA leading to direct local learning and collective action. This process, with trained facilitators, is anticipated to have covered the whole country by the end of 2005 (Joseph 2005). This is but one example of the many forms and potentials of PPAs.

\section{Hidden and Sensitive Dimensions}

Participatory methods, creatively evolved and carefully facilitated, have opened up aspects of life which have usually been thought too private, sensitive or dangerous to make public or to analyse. An early example (see also below) was wealth or wellbeing ranking, in which members of a community typically first draw a social map showing all households, then list these on cards, and then sort them into piles according to degrees of wealth or more usually some concept of wellbeing. Middle class urban professionals often regard this as either impossible, or unethical, supposing it will be demeaning and humiliating for those who are worse off. To an extraordinary degree these fears have repeatedly proved unfounded. Three other areas are gender relations and sexual and reproductive wellbeing, violence, insecurity and social abuses, and open defecation.

The first example is the related areas of gender relations, sexual behaviour and sexual and reproductive well-being. Participatory approaches and methods have 
proved potent in bringing these into the open, and empowering women to take action. Gender relations, and how they have been changing, were a major theme in the Voices of the Poor study (Narayan et al 2001 chapter 6 pp 109-132). Much has been explored and documented as never before in Realizing Rights: transforming approaches to sexual and reproductive well-being (Cornwall and Welbourn 2002). The lives and realities of those who are marginalised, despised, excluded and ignored have been brought out into the light. Sex workers, for example, come to life as people like other people, for whom respect, security and good relations matter as much, if not more, than they do for others. Participatory approaches to HIVIAIDS, especially through the group processes known as Stepping Stones (Welbourne 1995, 2002) have brought what was hidden or unspoken into the open, with frank talk about sex and death, concern for sensitive behaviour and relationships, acceptance of HIV-positive women and men, and counselling and care for the sick and dying. Participatory approaches and methods have also been developed for HIVIAIDS work with drug users (International HIVIAIDS Alliance 2003). Other areas are the sexual behaviours and preferences of adolescents ${ }^{i v}$ and of prepubescent children (unknown to their parents).

The second area is violence, physical insecurity and social abuses. Participatory studies of violence in Jamaica, Guatemala and Colombia have broken new ground, revealing wide differences between beliefs of policy-makers about forms of violence and the realities experienced by ordinary people. In Peru, participatory time lines, matrices and maps were used in Ayacucho as part of the Colectivo Yuyarisu ('We remember') process of the Truth Commission (Comision de la Verdad y Justicia): using these methods, over 100 groups recollected and reconstructed human rights violations which had taken place in the era of political violence 1980-94 (Francke 2003 and pers comm). In many contexts, domestic abuse and violence against women has been brought out into the open. An early example was an all-women's PRA activity in Tamil Nadu in 1990 (pers. comms. Sheelu Francis and John Devavaram) in which women mapped households and 
marked with a yellow circle those where the husband was a drunkard. The Voices of the Poor study included perceived prevalence and trends of domestic violence against women. Another illustration is the Internal Learning System introduced into parts of Indiav. Women individually and in groups keep visual diaries which they update every six months. In these they score from 1 to 5 for aspects of quality of life such husbands drinking, domestic violence, Dalits having to drink out of separate glasses, Dalits being made to carry dead bodies or dead animals, and whether a girl can select her life partner (pers. comms. Vimalanathan, S. Nagasundari and $H$. Noponen).

A third example is open defecation, widespread in South and Southeast Asia and a major source of sickness and mortality, and illbeing for women who lack access to the privacy of a latrine. They are subject to gross gender discrimination being compelled by custom, unlike men, to go unseen which without latrines means only before dawn or after nightfall. New participatory approaches are now enabling communities to confront and face the realities, often spurring them into action (Kar 2003). Community members are facilitated to make defecation maps, walk transects, inspect the defecation areas, confront the reality, draw flow diagrams, calculate the cartloads of shit produced and the amounts ingested, and are encouraged to take action on their own. The number of communities in South Asia that have now proudly declared themselves open defecation free now numbers thousands. The gains for the well-being of women is suggested by an inscription on a wall in a totally sanitised village in Maharashtra: 'Daughters from our village are not married to villages where open defecation is practised'. In rural South Asia, where open defecation is widespread, the sheer scale of the potential gains in health, reduced mortality, and wellbeing for millions of women, children and men is so vast that it is difficult fully to appreciate.

The importance of opening up these subjects can scarcely be exaggerated. When they are not surfaced, analysed and confronted, much avoidable illbeing persists. Conversely, the potential for enhanced well-being from improving 
sexual and gender relations, from tackling and reducing or eliminating violence in its many forms, and from ending open defecation with gains in health and especially for the well-being especially for women and children but also for men each of these can only be described as phenomenal. Participatory approaches and methods, well facilitated, cannot solve these alone; but there is enough evidence now to realise that they can establish bridgeheads with the possibility of becoming transformative movements which spread on their own.

Nets and webs of disadvantage and deprivation

We now come to the issue of the multiplicity of dimensions of poverty. When dimension is used in the inclusive sense of this paper, it includes many aspects of disadvantage. In the analysis of the Voices of the Poor study we faced difficult practical issues of how to analyse a large amount of data, most of it qualitative, but some also (see below, next section) amenable to aggregation and quantification". We were continually impressed by how the dimensions of deprivation which emerged from the participatory data were interlinked, and we increasingly saw these links as a net or web in which poor people were trapped. Two diagrams were published (figures 1 and 2). ${ }^{\text {vi }}$ And two others were not (figures 3 and 4).

Figure 1, Development as good change: From illbeing to wellbeing, was a manifestation of pentaphilia (the love of $5 \mathrm{~s}$ of a thing) a condition from which 1 have been unable to rid myself. Using it, we sought to express five composite dimensions of illbeing and wellbeing, and their interlinkages. Development could be seen as shifting from illbeing to wellbeing with equity, with interventions to enhance wellbeing possible at any of the five points.

[figure 1 about here]

Figure 2, Dimensions of powerlessness and illbeing, expanded the circles to ten 
As the diagram indicates, each of these in turn can take various forms. And combining in powerlessness symbolised by the net.

[figure 2 about here]

By specifying these characteristics of disadvantage, figure 2 again raises a potential agenda for intervention with any one of them, and questions of how they interlink and reinforce each other. In any story of the life of a poor person, linkages can be traced.

The versatility and power of these ways of presenting multiple dimensions and causal links can also be illustrated with two further diagrams.

Figure 3, also inspired by the Voices experience (and in part shown in Narayan et al 2000: 97) shows two body syndromes. These express several ways in which a weak or hungry body can be part of self-reinforcing syndrome, including reducing the power to bargain, and how less money can mean delayed and lower quality medical treatment. These were both aspects of disadvantage which the Voices evidence presented.

[figure 3 about here]

Figure 4 may be regarded by some as over the top in terms of complexity However, all 13 of these dimensions

- material lack

- vulnerability and insecurities

- bad social relations

- physical weakness - the body, exhaustion

- location - places of the poor

- poverty of time

- seasonal dimensions

- capabilities

- disregard and abuse by the more powerful

- ascribed and legal inferiority 
- lack of information

- lack of access to services

- lack of political clout

have been articulated and diagrammed by poor people, using variations and combinations of mapping, listing, Venn diagrams, pie diagrams, pile sorting, matrix scoring, pairwise ranking, time lines and seasonal diagrams, wealth and wellbeing ranking and sorting.

They do, though, raise analytical and practical questions. We can ask whether the many aspects and linkages presented are credible, and how many of them are found and function for any person, group or set of conditions. If we conflate or eliminate dimensions, are we then in danger of failing to identify crucial disadvantages? As the diagram indicates, each of these in turn can take various forms. Another question is whether figures 2 and 4 overstress the negative, in ways in which figures 1 and 3 do not because they indicate the potential for transitions (though, of course, these can go either way).

A question remains: whose analysis and categories are to be privileged? These are "ours", those of professionals who are not themselves poor. The words, concepts, categories and priorities of poor people, especially illustrated by the way they were elicited and expressed in the Voices of the Poor, were rich and varied, but with commonalities. There are trade-offs to be puzzled over, between "their" realities and ours, between local participatory diversity and commensurability for aggregation, and between many categories representing poor people's realities, and fewer categories more manageable for outsider professionals.

Four neglected dimensions 
Four dimensions have been so relatively neglected in the professional literature of which I am aware, that I will touch on them here.

\section{Tropical seasonality}

The interacting seasonal disadvantages include: viil

- hard work in cultivation

- sickness (malaria, Dengue fever, diarrhoeas, skin sores and diseases, snake bite, Guinea worm disease..

- lack of food. The hungry season

- poor quality and rapidly contaminated food.

- physical weakness and exhaustion from combinations of the above

- shortage of money, loans in kind with very high implicit interest rates

- isolation with difficult or no access to markets and medical treatment

- late pregnancy and childbirth

- shelter and housing collapsing, leaking, flooded

- wet and cold

- the high opportunity cost of not being able to work

- neglect and exposure of children

Season-proofed as they are against all of these, professionals living in urban centres underperceive the multiple interactions of disadvantage for poor people living in rural areas during tropical rains, especially those areas which are "remote". During the rains, travel is often restricted to tarmac roads. Those off the tarmac and especially those "cut off" during the rains, are not visited, met or heard.

\section{Places of the poor}

A whole chapter in Voices of the Poor (Narayan et al 2000: 71-88) came to be concerned with the places where poor people live and work. This was not 
foreseen in the planning of the study, but emerged as the findings were collected and sorted. The places where poor people live suffer combinations of isolation, lack of infrastructure, lack of services, crime, pollution, and vulnerability to disasters like drought, floods and landslips. Stigma of urban place can mean that place of residence must be concealed or dissembled when applying for a job. Inordinate amounts of time may be required for obtaining basics like water. The Chronic Poverty Report 2004-05 devotes a whole chapter (CPRC 2005: 26-35) to "Where do chronically poor people live?" and does a service by describing and analysing spatial poverty traps, their ecological characteristics, poor infrastructure, weak institutions and political isolation. Place, whether rural or urban, jas an interlocking dimension of deprivation is so obvious that it is strange that it has not received more prominence. It should be harder to overlook now that it has been named. ${ }^{x}$

\section{Poverty of time and energy}

Some of the poorest wish they had work. A very poor woman in a Bangladesh village said:

"These days I have no work," she complains. "If we had land, I would always be busy - husking rice, grinding lentils, cooking three times a day. You've seen how hard Jolil's wife works, haven't you? I have nothing to do, so I watch the children and worry. What kind of life is that?" Hartmann and Boyce 1983: 166-7)

There can be poverty of too much time, and poverty of too little. The evidence from the Voices of the Poor study suggested that unwelcome surplus time was becoming more common for men, with unemployment, and poverty of both time and energy becoming more common for women. This latter poverty of time and energy was recognised in the South African PPA (May with others 1998: 108-

109). It has become more acute for many women as they have become 
breadwinners in addition to their domestic and reproductive roles (Narayan et al 2000: 111-4). When asked what her dream was, a poor rural woman in Zambia said that it was to be able to go to town, spend time with her friends, and come back again (PRA Report video).

\section{The body}

Deriving from their review of over 250 life-stories of poor people, Parasuraman and his co-authors devote a chapter of Listening to People Living in Povertv to "The Labouring Body" (274-297), which they point out is often the only resource a person living in poverty is able to use.

"The continuous exertion of their bodies in labour that is underpaid and undervalued leaves them exhausted. Their work is hazardous, seasonal and leaves them vulnerable to outside harm. They are forced to use and sell their bodies as an instrument. They rarely have time to recuperate or rest, and are reduced to what their bodies can do. These processes inscribe on their bodies and leave them to diseases, degenerating illnesses and death" $\quad$ (ibid:293) ${ }^{\mathrm{x}}$

The central importance of the body to most poor people has tended to be under recognised. The slogan at the head of a poster of the trade union SEWA (the Self-Employed Women's Association) in India reads: OUR BODIES ARE OUR CAPITAL. The body is more important to people living in poverty than it is to professionals. For many, it is their most important asset. But it is at the same time vulnerable, uninsured and indivisible. It has often been weakened by life experiences. It is exceptionally exposed and vulnerable - to hard and dangerous work and accidents, to violence, to sickness, to lack of nutrition, overwork and exhaustion. With an accident or illness it can flip suddenly from being main asset to liability, needing payment for treatment and having to be fed and cared for. It is a recurrent finding that many fall into bad conditions of deep poverty because 
of what has happened to their bodies. Yet in general, the priority to poor people of quick, effective and affordable treatment has been under-recognised by professionals. In addition to human and ethical aspects, it may cost much less, and be more feasible, to provide good curative services to enable poor people to avoid becoming poorer than it is, once they are poorer, to enable them to claw their way back up again.

\section{Negative synergies}

These four neglected dimensions, like others, interact with negative synergies.. A poor woman in the Gambia, referring to what could happen during the agricultural season of the rains, said: "Sometimes we are overcome by weeds through sickness or accidents". With seasonal vulnerability of the body, in places which are isolated or cut off, and with seasonal poverty of time and energy when time and energy have high opportunity costs, the disadvantages are compounded, but in ways which are not readily visible to professionals. It is a cruel twist that poor people are kept waiting in clinics while better dressed middle class people see health staff straight away ${ }^{\times i}$. In terms of human wellbeing foregone by waiting, the time of the poor people can be far, far more valuable. But this is neither recognised nor acted on. Following any logic of optimising wellbeing, it is the middle classes who should have to wait.

\section{Participation and numbers}

In recent years increasing attention has been paid to combining qualitative and quantitative methods in research (e.g. Booth et al 1998; Marsland et al 2000; Kanbur 2003). Complementarities have been recognised between the depth and detail contributed by qualitative research and the representativeness and statistical robustness contributed by quantitative research ${ }^{\mathrm{x}}$. The benefits of such combinations are not now seriously in dispute. They do, though, tend to overlook the power and potential of participatory approaches and methods. In 
this connection, two assumptions are still quite common: first, that participatory approaches only generate qualitative insights; and second, that quantitative data can only be produced by questionnaire surveys or scientific measurement.

To the contrary, numerous experiences have shown both these assumptions to be false. Since the early 1990s, a quiet tide of innovation has developed a rich range of participatory ways by which local people can themselves produce numbers ${ }^{x i i}$. The methodological pioneers have rarely recognised the full significance of what they have been doing and have often not written up what they have done, or made it easy for others to learn from them. They have worked in the NE quadrant of figure 5 that has been largely overlooked by mainstream professions and professionals. The results have been as striking and exciting as they have been unrecognised in professional mainstreams.

[figure 5 about here]

There are now many examples of numbers being generated by participatory processes and of statistical analysis of these ${ }^{\mathrm{xiv}}$. The evidence to date indicates that numbers generated by participatory processes are usually more accurate and more useful than those from questionnaires. Some questionnaires will always be needed, and some, especially time series like the National Sample Survey in India, should surely continue. But for most investigations needing numbers questionnaires may now best be only a last resort. Since this statement may be greeted with scepticism, let me lay out some of the experience and evidence.

Participatory analytical activities and applications can generate numbers through counting, measuring, estimating, valuing, ranking, and scoring. Making comparisons is often involved, giving numbers or scores to indicate relative values. Analytical activities are many, for example:

- Mapping

- Modelling 